\title{
Processo de Projeto Integrado e desempenho ambiental de edificações: os casos do SAP Labs Brazil e da Ampliação do CENPES Petrobras
}

\author{
Integrated Design Process and environmental \\ performance of buildings: the cases of SAP Labs Brazil \\ and Expansion of CENPES Petrobras
}

\section{Francisco Gitahy de Figueiredo Vanessa Gomes da Silva}

\section{Resumo}

Francisco Gitahy de Figueiredo Arquiteto e urbanista Spinazzola e Gitahy Arquitetura Rua General J ardim, 618, cj. 91 Vila Buarque São Paulo - SP - Brasi CEP 01223-010 Tel.: (11) 2761-1229 E-mail: chicogitahy@gmail.com

Vanessa Gomes da Silva Departamento de Arquitetura e Construção

Faculdade de Engenharia Civil, Arquitetura e Urbanismo Universidade Estadual de Campinas

Av. Albert Einstein, 951

Cidade Universitária

Campinas - SP- Brasil CEP 13083-852

Tel.: (19) 3521-2411

E-mail: vangomes@fec.unicamp.br

Recebido em 16/04/10

Aceito em 15/04/12

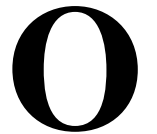

Processo de Projeto Integrado (PPI) estimula o trabalho multidisciplinar dos vários agentes desde o início do processo de projeto. Foi proposto para uma pesquisa investigar como o PPI pode contribuir para a melhoria do desempenho ambiental de edificações, a partir de dois estudos de caso desenvolvidos no Brasil. A abordagem metodológica apoiou-se no desenvolvimento prévio de proposições teóricas - neste caso, uma referência teórica de PPI, compreendendo seus elementos metodológicos fundamentais - para orientar as etapas de investigação e análise de dois processos de projeto de empreendimentos com elevadas metas de desempenho ambiental. O objetivo deste artigo é apresentar os principais resultados relacionados à documentação dos estudos de caso e à análise dos dados, constituída pelo posicionamento dos estudos de caso em relação à referência teórica, assim como discutir as principais lições aprendidas. Os resultados indicam que, em ambos os empreendimentos, os elementos do PPI presentes foram muito importantes para o alcance das metas definidas. No entanto, em nenhum deles os elementos metodológicos que caracterizam a abordagem PPI foram completamente incorporados.

Palavras-chave: Sustentabilidade. Arquitetura. Desempenho ambiental. Processo de projeto.

\section{Abstract}

The Integrated Design Process (IDP) encourages multidisciplinary collaboration among several actors involved, from the beginning of the design. The aim of this research study was to investigate how IDP can contribute to a better environmental performance of buildings, based on two case studies carried out in Brazil. The methodological approach was based on the previous establishment of theoretical propositions - in this case, the IPD theoretical framework, consisting of the fundamental elements of this approach - to guide data collection and analysis of two projects with ambitious environmental goals. This paper aims to present the main findings related to case study documentation and data analysis, which consisted ofe positioning of the cases studies in relation to the theoretical framework, as well as to discuss the main lessons learned. The results indicate that in both projects the existing IPD elements had a positive influence on the achievement of the overall targets. However, none of them completely incorporated the fundamental methodological elements that characterize the IPD.

Keywords: Sustainability. Architecture. Environmental performance. Design process. 


\section{Introdução}

Em meio ao debate da sustentabilidade na construção civil, o Processo de Projeto Integrado (PPI) vem sendo considerado um poderoso recurso para o atendimento a demandas socioambientais mais rigorosas.

Os critérios de desempenho ambiental incluem:

(a) consumo mínimo de recursos não renováveis (combustíveis fósseis, água, materiais e solo);

(b) minimização de emissões relacionadas a efeito estufa e acidificação, de efluentes líquidos e de resíduos sólidos; $\mathrm{e}$

(c) minimização de impactos negativos em ecossistemas locais.

Sob a perspectiva de longo prazo inerente ao conceito de sustentabilidade, tanto os aspectos que potencialmente estendam a vida útil, como adaptabilidade, flexibilidade e durabilidade, quanto os custos no ciclo de vida - complementarmente aos custos iniciais - também devem ser levados em consideração. Finalmente, a dimensão social da sustentabilidade demanda, na escala da edificação, a maximização da qualidade do ambiente interno (qualidade do ar, conforto térmico, luminoso e acústico), bem como a implementação de meios de produção socialmente mais justos e equilibrados com as comunidades do entorno de inserção. É fundamental que esses critérios sejam considerados conjuntamente, mas processos convencionais de projeto apresentam sérias limitações para isso.

A prática típica de projeto é caracterizada por um processo segmentado e pelo isolamento entre as disciplinas. Durante as primeiras etapas, as soluções são desenvolvidas apenas pelo escritório de arquitetura e validadas pelo cliente, enquanto a contratação dos demais projetistas costuma ocorrer apenas nas etapas finais, quando os principais conceitos já estão definidos e as possibilidades de alteração são muito restritas. Essas características e uma profunda separação entre as etapas de projeto e construção são apontadas como causadoras de muitas dificuldades para 0 atendimento às demandas do empreendimento (MELHADO, 2001; FABRÍCIO, 2002; INTERNATIONAL..., 2003).

Por um lado, percebe-se que as oportunidades de alterações e melhorias significativas são grandes no início e diminuem rapidamente ao longo das etapas. Por outro, para a incorporação de metas mais rigorosas de desempenho, sejam funcionais, ambientais, construtivas ou de custo ao longo do ciclo de vida do edifício, é fundamental considerar as interdependências entre os subsistemas e desenvolvê-los de forma integrada. Por essas razões, o PPI supõe o trabalho multidisciplinar integrado dos vários agentes envolvidos (cliente, arquiteto, projetistas, construtora, consultores, etc.) desde o início do processo de projeto, sendo um dos primeiros passos a discussão e definição de um consenso entre cliente e projetistas quanto aos objetivos, metas de desempenho, meios, papéis e responsabilidades.

Esses elementos aparecem em um conjunto de publicações elaborado pela International Energy Agency, reunindo metodologias e ferramentas para orientar processos de projeto com demandas de desempenho ambiental (INTERNATIONAL..., 2003). O processo proposto foi denominado Integrated Design Process (IDP), aqui traduzido como Processo de Projeto Integrado. O tema vem sendo amadurecido nos últimos anos. Kibert (2005) e The American Institute of Architects (2007) discutem oportunidades, limitações e alterações necessárias em processos de entrega de empreendimentos para a implementação dos elementos metodológicos do PPI. Dois guias, elaborados respectivamente por Busby, Perkins + Will e Stantec Consulting (2007) e 7group e Reed (2009), são bastante completos, com conceitos, princípios fundamentais, etapas e atividades muito bem caracterizados.

Autores brasileiros, focando a gestão de processos de projeto e produção de edifícios, também defendem a constituição de equipes multidisciplinares desde o início do processo de projeto, com uma clara definição dos meios para a coordenação eficaz das atividades e interações entre disciplinas (MELHADO, 1994; 2001; FABRÍCIO, 2002; ROMANO, 2003). Melhado (2001) denomina a integração entre os trabalhos multidisciplinares e entre as etapas de projeto e produção do edifício de Projeto Simultâneo do Produto e de sua Produção (PSPP), emprestando de outros setores da indústria o conceito de engenharia simultânea.

Atualmente, existem vários exemplos de processos de projeto internacionais com essas características, e estudos documentados revelam a eficácia das novas metodologias. Torcellini et al. (2006) apresentam seis exemplos de PPI dos Estados Unidos, com reduções no consumo anual de energia de $25 \%$ a $70 \%$, documentados também em relatórios individuais, nos quais o desempenho energético das edificações foi avaliado pelo National Renewable Energy Laboratory (NREL), dos Estados Unidos. Entre estes, pode-se destacar o projeto do Zion National Park Visitors Center, nos Estados Unidos (TORCELLINI et al., 2005), 
pois o relatório contém um registro bem caracterizado do processo de projeto. O edifício alcançou uma redução nos custos de energia de $67 \%$ em relação ao modelo-base de referência, em grande parte devido aos elementos metodológicos empregados desde o início, tais como:

(a) trabalho multidisciplinar integrado;

(b) definição consensual das metas de desempenho; e

(c) uso de ferramentas computacionais de simulação.

\section{Objetivo e abordagem metodológica}

Foi proposto para uma pesquisa investigar, a partir de dois estudos de caso brasileiros, como o PPI pode contribuir para a melhoria do desempenho ambiental de edificações. A abordagem metodológica, explicada detalhadamente por Figueiredo (2009), é resumida a seguir.

Como em estudos de caso há muito mais variáveis de interesse do que pontos de dados e, consequentemente, eles baseiam-se em fontes múltiplas de evidências, um desenvolvimento prévio de proposições teóricas para orientar a coleta e a análise de dados pode beneficiar muito a pesquisa (YIN, 2005). Por essa razão, a primeira etapa da pesquisa correspondeu ao estabelecimento de uma referência teórica, compreendendo os elementos metodológicos fundamentais que caracterizam PPIs. Esta orientou as atividades das quatro etapas seguintes (Figura 1).

A Figura 2 resume os cinco elementos metodológicos de PPI que compõem a referência teórica. Eles foram definidos a partir do estudo da literatura, podendo-se destacar os autores International Energy Agency (2003), Busby, Perkins + Will e Stantec Consulting (2007) e 7group e Reed (2009).

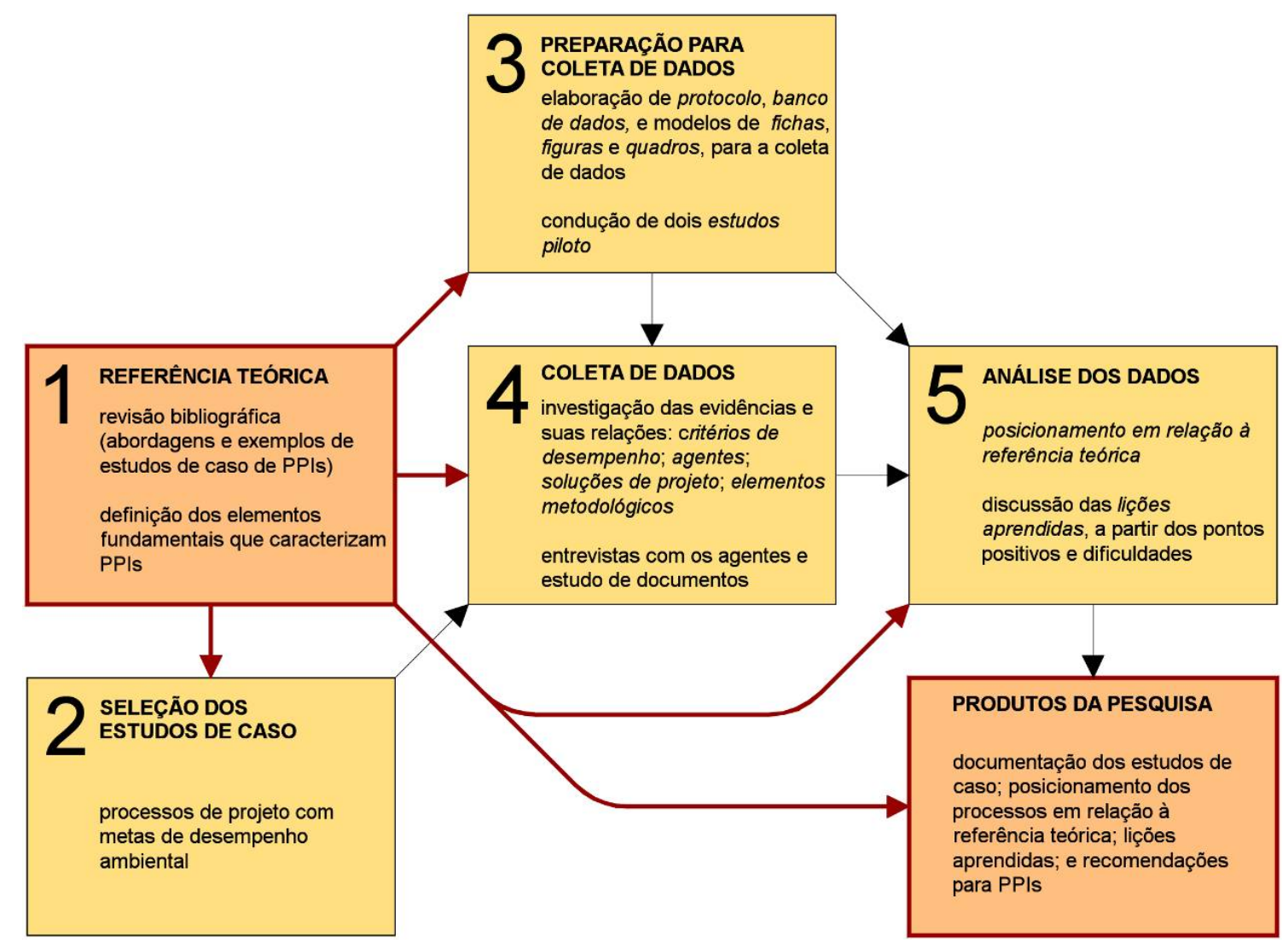

Figura 1 - Etapas da pesquisa

Fonte: baseado em Figueiredo (2009, p. 65). 
A Figura 3, que representa as etapas do PPI, ilustra a necessidade de constituir a equipe completa logo no início e mantê-la ao longo de todo o processo. Da mesma forma, os cinco elementos metodológicos fundamentais devem ser empregados ao longo de todas as etapas de projeto e construção. Na etapa de Uso e Operação, a Avaliação de Desempenho do Edifício (ADE) deve continuar, verificando-se o atendimento às metas definidas para o projeto.

Com base em experiências de PPI na Europa e na América do Norte, constatou-se que cada etapa do processo é caracterizada por ciclos iterativos, nos quais as alternativas são formuladas, testadas e reformuladas até encontrar-se a melhor solução (INTERNATIONAL..., 2003). Esses ciclos também estão representados na Figura 3. Malin (2004) observa que processos iterativos também ocorrem em processos convencionais, mas de forma predominantemente isolada em cada disciplina, para o desenvolvimento de diferentes subsistemas, enquanto em PPIs a equipe trabalha colaborativamente para desenvolver todos os aspectos do projeto. Um exame mais aprofundado desses elementos, incluindo recomendações detalhadas para as etapas de PPI, é feito por Figueiredo e Silva (2010).

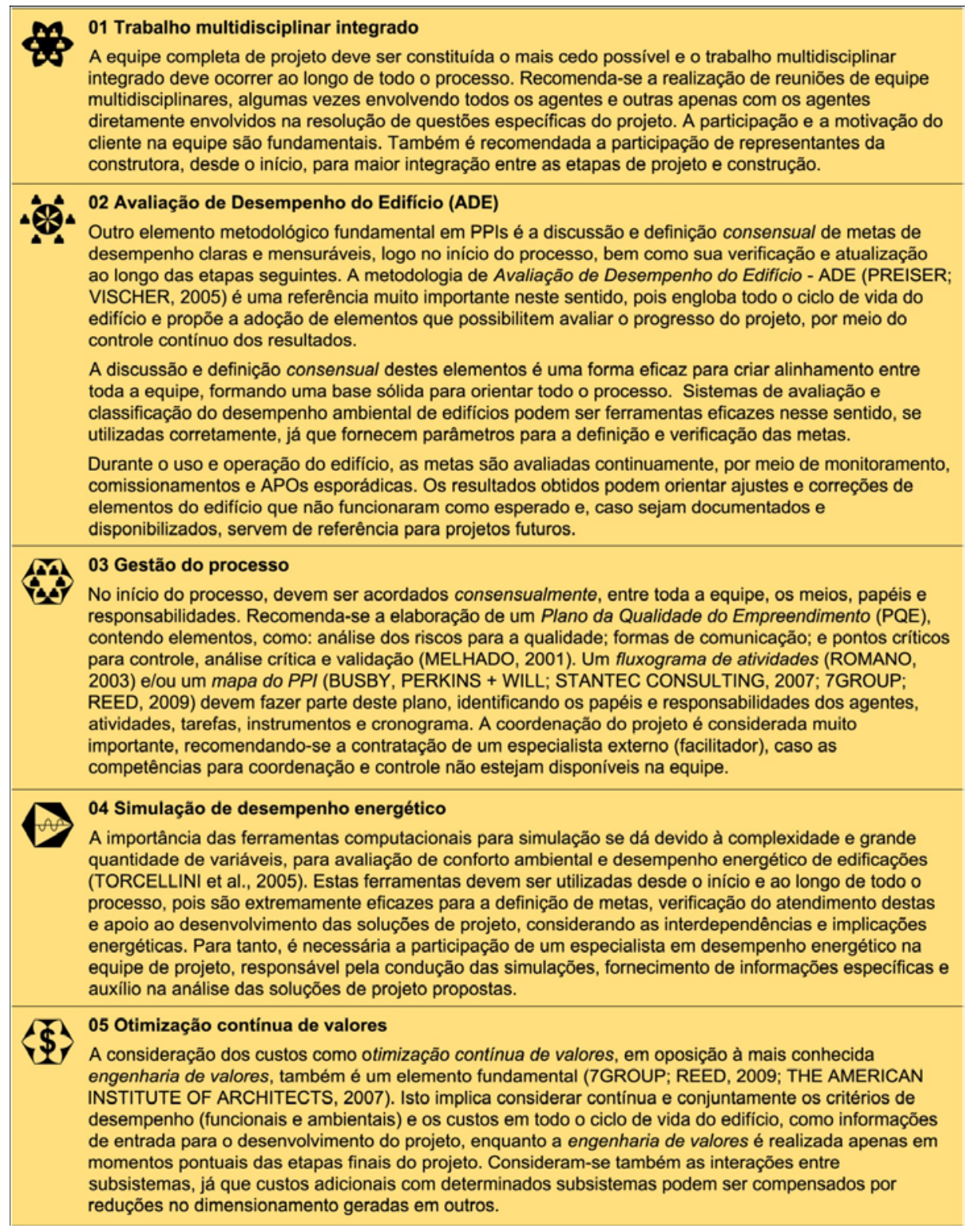

Figura 2 - Elementos metodológicos do PPI

Fonte: baseado em Figueiredo (2009, p. 67). 


\begin{tabular}{|c|c|c|c|}
\hline \multicolumn{3}{|c|}{ elementos metodologicos } & \multirow[b]{2}{*}{$\begin{array}{l}\text { elaboração do programa de necessidades e } \\
\text { realização de análise detalhada do local }\end{array}$} \\
\hline 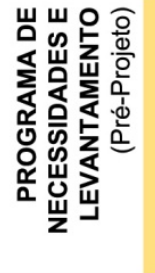 & $\begin{array}{l}\text { cliente (proprietário, gerente de operações e } \\
\text { usuários) } \\
\text { arquiteto, projetistas (estrutura, } \\
\text { ar condicionado, elétrica, hidráulica, } \\
\text { luminotécnica, automaçâo, paisagismo, outros) } \\
\text { e consultores (eficiência energética, outros) } \\
\text { consultor de custos } \\
\text { representante da construtora } \\
\text { autoridade de comissionamento }\end{array}$ & is. & \\
\hline 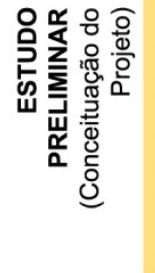 & $\begin{array}{l}\text { cliente (proprietário, gerente de operaçōes e } \\
\text { usuários) } \\
\text { arquiteto, projetistas (estrutura, } \\
\text { ar condicionado, elétrica, hidráulica, } \\
\text { luminotécnica, automaçăo, paisagismo, outros) } \\
\text { e consultores (eficiência energética, outros) } \\
\text { consultor de custos } \\
\text { representante da construtora } \\
\text { autoridade de comissionamento }\end{array}$ & ث. & $\begin{array}{l}\text { conceituação do projeto: volume, orientação, } \\
\text { envoltória e sistemas do edifício } \\
\text { (condicionamento, iluminação, uso racional } \\
\text { de água, outros) } \\
\text { verificação, atualização das metas e } \\
\text { comissionamento do projeto }\end{array}$ \\
\hline 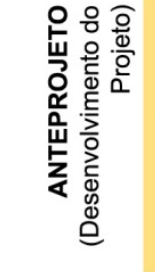 & $\begin{array}{l}\text { cliente (proprietário, gerente de operaçōes e } \\
\text { usuários) } \\
\text { arquiteto, projetistas (estrutura, } \\
\text { ar condicionado, elétrica, hidráulica, } \\
\text { luminotécnica, automação, paisagismo, outros) } \\
\text { e consultores (eficiência energética, outros) } \\
\text { consultor de custos } \\
\text { representante da construtora } \\
\text { autoridade de comissionamento }\end{array}$ & $\$$ & $\begin{array}{l}\text { desenvolvimento dos conceitos } \\
\text { estabelecidos e definição das soluções, } \\
\text { sistemas e especificações de componentes } \\
\text { e materiais } \\
\text { verificação, atualização das metas e } \\
\text { comissionamento do projeto }\end{array}$ \\
\hline 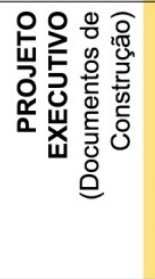 & $\begin{array}{l}\text { cliente (proprietário, gerente de operações e } \\
\text { usuários) } \\
\text { arquiteto, projetistas (estrutura, } \\
\text { ar condicionado, elétrica, hidráulica, } \\
\text { luminotécnica, automação, paisagismo, outros) } \\
\text { e consultores (eficiência energética, outros) } \\
\text { consultor de custos } \\
\text { representante da construtora } \\
\text { autoridade de comissionamento }\end{array}$ & $\$ \$$ & $\begin{array}{l}\text { elaboração dos documentos de construção, } \\
\text { com base nas definições da etapa de } \\
\text { desenvolvimento } \\
\text { verificação, atualização das metas e } \\
\text { comissionamento do projeto }\end{array}$ \\
\hline 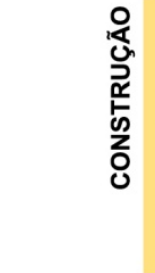 & $\begin{array}{l}\text { cliente (proprietário, gerente de operaçōes e } \\
\text { usuários) } \\
\text { arquiteto, projetistas (estrutura, } \\
\text { ar condicionado, elétrica, hidráulica, } \\
\text { luminotécnica, automação, paisagismo, outros) } \\
\text { e consultores (eficiência energética, outros) } \\
\text { consultor de custos } \\
\text { construtora } \\
\text { autoridade de comissionamento }\end{array}$ & 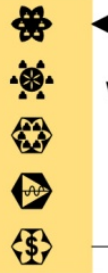 & $\begin{array}{l}\text { execução do edifício, conforme os } \\
\text { documentos de construção } \\
\text { verificação, atualização das metas e } \\
\text { comissionamento pré-entrega dos sistemas } \\
\text { do edifício }\end{array}$ \\
\hline 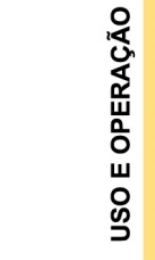 & $\begin{array}{l}\text { cliente (proprietário, gerente de operações e } \\
\text { usuários) } \\
\text { arquiteto, projetistas (estrutura, } \\
\text { ar condicionado, elétrica, hidráulica, } \\
\text { luminotécnica, automação, paisagismo, outros) } \\
\text { e consultores (eficiência energética, outros) } \\
\text { consultor de custos } \\
\text { autoridade de comissionamento }\end{array}$ & * & $\begin{array}{l}\text { monitoramento contínuo, } \\
\text { recomissionamentos e realização de APOs } \\
\text { esporádicas, para verificação das metas } \\
\text { definidas no projeto, correções e ajustes, } \\
\text { retroalimientação para projetos futuros }\end{array}$ \\
\hline & $\begin{array}{l}\text { trabalho multi } \\
\text { integrado } \\
\text { simulação de } \\
\text { desempenho }\end{array}$ & idisciplinar & $\begin{array}{l}\text { ação de Desempenho } \\
\text { ificio (ADE) } \\
\text { zação continua } \\
\text { lores }\end{array}$ \\
\hline
\end{tabular}

\section{Figura 3 - Etapas do PPI}

Fonte: baseada em Figueiredo (2009, p. 68).

A segunda etapa correspondeu à seleção dos estudos de caso: dois processos de projeto de edificações nacionais que partilham os fatos de:

(a) terem sido iniciados após concorrência por carta-convite para o projeto; e (b) estarem em processo de avaliação e certificação ambiental por meio da ferramenta LEED $^{\text {TM }}$ NC - Novas Construções ${ }^{1}$.

\footnotetext{
${ }^{1} O$ LEED ${ }^{T M}$ é um sistema de avaliação e certificação ambiental desenvolvido pelo US Green Building Council (USGBC), inicialmente com financiamento do National Institute of Standards and Technology (NIST), dos Estados Unidos (US GREEN..., 2007).
} 
Em seguida, foi conduzida uma terceira etapa de preparação para coleta de dados. Elaborou-se um protocolo para coleta de dados, no qual foram identificados os seguintes tipos de evidência (Figura 4):
(a) elementos metodológicos do PPI;
(b) metas de desempenho;
(c) agentes; $\mathrm{e}$
(d) soluções de projeto.

Foram elaborados também os seguintes instrumentos, que constituíram o banco de dados da pesquisa:

(a) fichas de registro e análise de evidências;

(b) fichas-guia para entrevistas ${ }^{2}$; e

(c) questionário de avaliação da gestão do processo de projeto.

A quarta etapa de coleta de dados foi realizada por meio de entrevistas e estudo de documentos de projeto, entre novembro de 2008 e julho de 2009, visando investigar a ocorrência das evidências em cada etapa e as relações entre elas ${ }^{3}$. Para o estudo de caso 1, foram entrevistados os agentes:
(a) arquitetos autores do projeto;
(b) arquiteto coordenador;
(c) projetista de estruturas;
(d) projetistas de ar condicionado, também responsáveis pela condução de simulações de energia;

(e) projetista de luminotécnica;

(f) projetista de automação;

(g) projetista de paisagismo;

(h) consultor de conforto térmico e acústico;

(i) consultor de esquadrias;

(j) representante da gerenciadora;

(k) especialista em sistema de certificação LEED ${ }^{\mathrm{TM}}$; e

(l) representantes do cliente, incluindo a arquiteta consultora e o engenheiro eletricista, atual gerente de operações do edifício.

\footnotetext{
${ }^{2}$ As fichas-guia foram cuidadosamente desenvolvidas para cada entrevista, com questões gerais sobre o processo; questões específicas sobre o escopo e participação no processo de cada um; e questões específicas desta investigação que ainda precisavam ser coletadas, resultantes do mapeamento das evidências.

${ }^{3}$ Dessa forma, o desenvolvimento de determinada solução de projeto foi investigado, verificando-se (1) em quais etapas foi concebida e se ocorreram alterações significativas; (2) quais os agentes envolvidos; e (3) quais os elementos metodológicos relacionados.
}

Para o estudo de caso 2, foram entrevistados os agentes:

(a) arquiteta coordenadora de projetos (duas entrevistas);

(b) projetista de estruturas;

(c) projetista de instalações hidrossanitárias; projetista de ar condicionado;

(d) projetista de paisagismo;

(e) pesquisadora da equipe de consultoria em ecoeficiência;

(f) consultor de esquadrias; e

(g) especialista em sistemas de certificação ambiental (que está dando apoio ao processo de certificação LEED ${ }^{\mathrm{TM}}$ na etapa de obra).

Pretendia-se entrevistar representantes do cliente e de todas as disciplinas de projeto e consultoria envolvidas no processo, mas isso não foi possível devido à indisponibilidade de agenda de alguns dos agentes no período da coleta de dados. A investigação buscou resgatar a história de cada processo, ressaltando as principais dificuldades, os pontos positivos e os resultados alcançados. As metas de desempenho ambiental foram investigadas a partir dos resultados preliminares das avaliações com a ferramenta LEED ${ }^{\mathrm{TM}}$.

A análise dos dados (quinta etapa) visou posicionar os estudos de caso em relação à referência teórica; e discutir as lições aprendidas, a partir das experiências mais significativas, dificuldades e pontos positivos constatados.

O objetivo deste artigo é apresentar os principais resultados relacionados aos seguintes produtos desta pesquisa:

(a) documentação dos estudos de caso; e

(b) análise dos dados. 


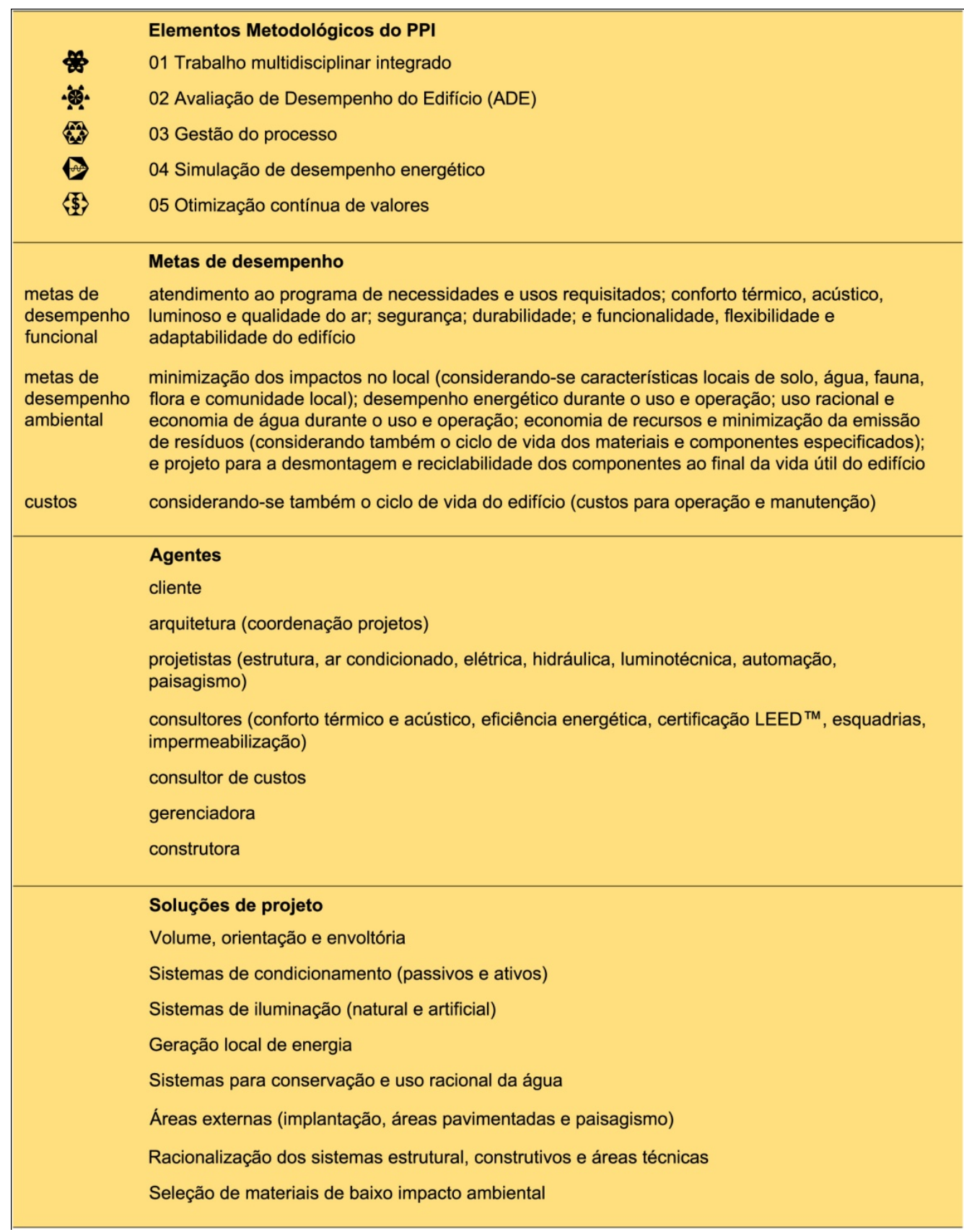

Figura 4 - Tipos de evidência

Fonte: baseada em Figueiredo (2009, p. 72-73).

\section{Estudo de caso 1: SAP Labs Brazil}

O primeiro estudo de caso é o processo de projeto de um edifício para abrigar o SAP Labs Brazil, em São Leopoldo, RS (Figura 5).

A empresa multinacional SAP atua na área de desenvolvimento de softwares e sistemas. O projeto de arquitetura foi desenvolvido pela Eduardo de Almeida Arquitetos Associados em coautoria com a Shundi Iwamisu Arquitetos Associados, que venceram a concorrência na modalidade carta-convite realizada em março e abril de 2007. Estão previstas duas fases para a implantação do edifício (Figura 6), em terreno de 23.014,39 $\mathrm{m}^{2}$. A investigação realizada é referente ao processo de projeto da primeira fase, concluída em junho de 2009, para implantação de edifício composto de dois blocos paralelos, com área total construída de 6.967,45 m². 


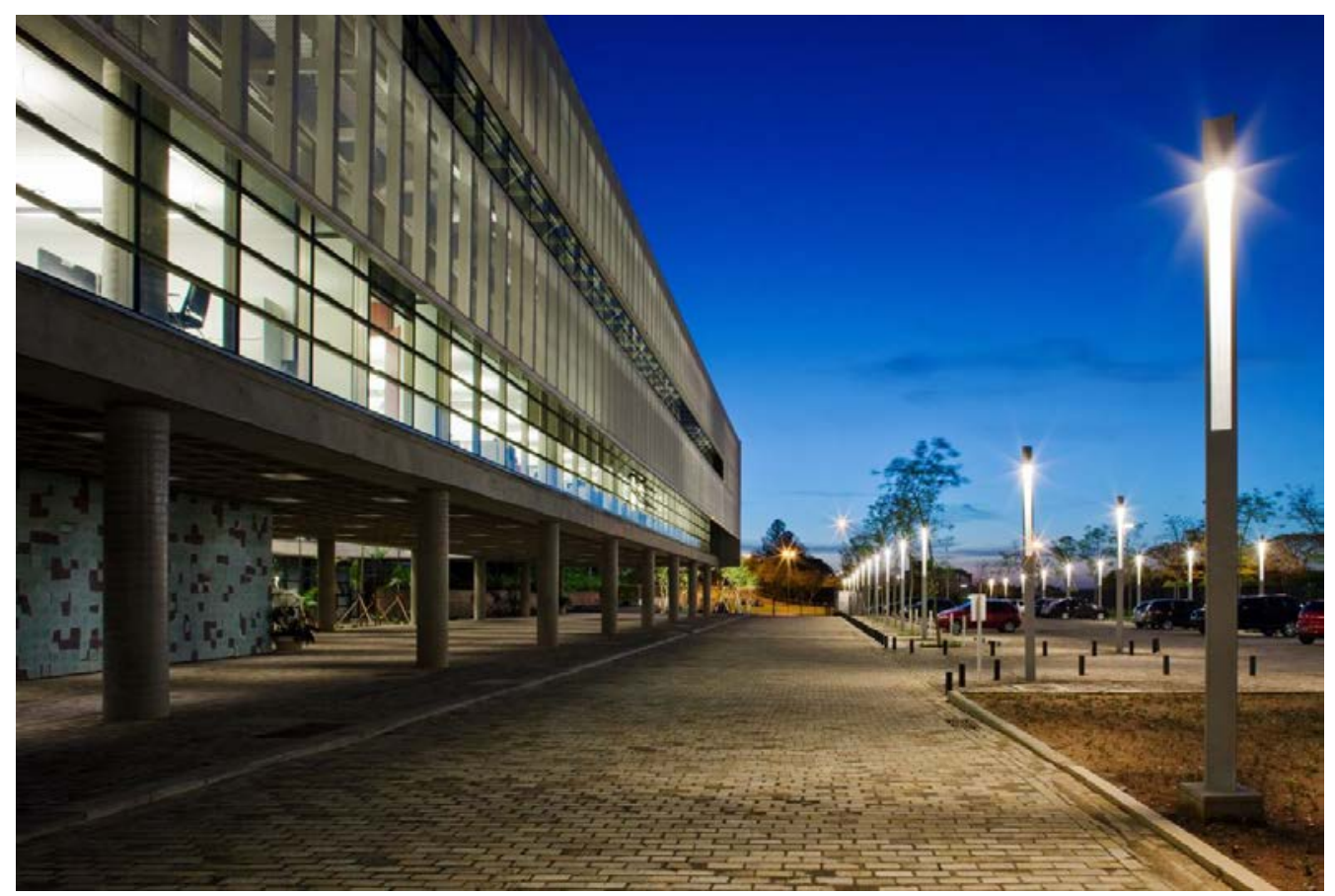

Figura 5 - SAP Labs Brazil

Fonte: imagem gentilmente cedida pela Eduardo de Almeida Arquitetos Associados e Shundi Iwamisu Arquitetos Associados.

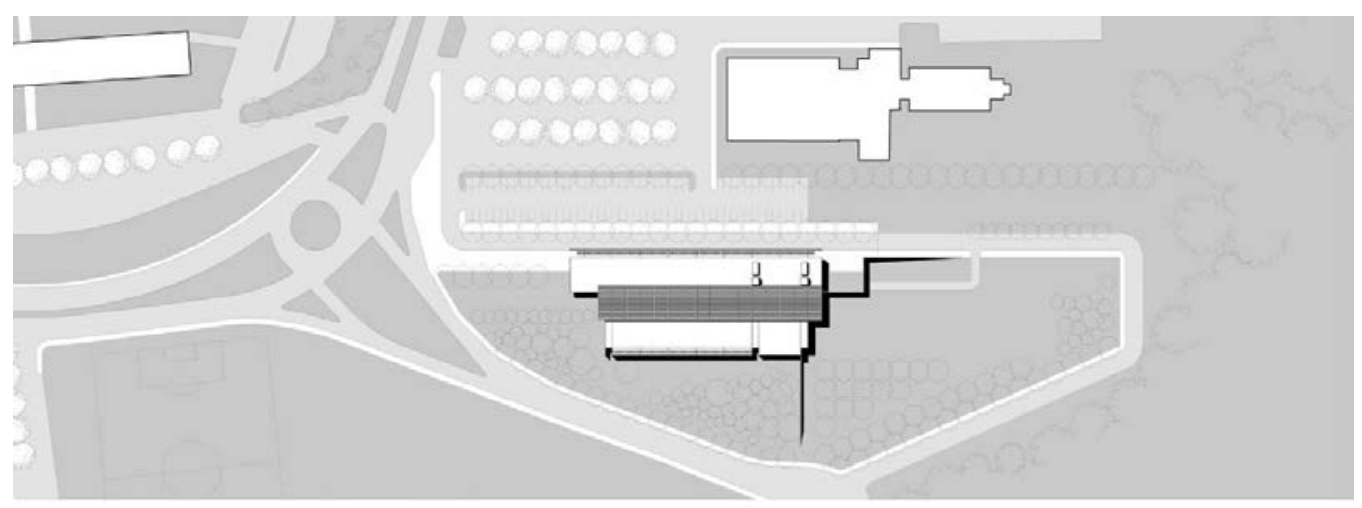

fase 1

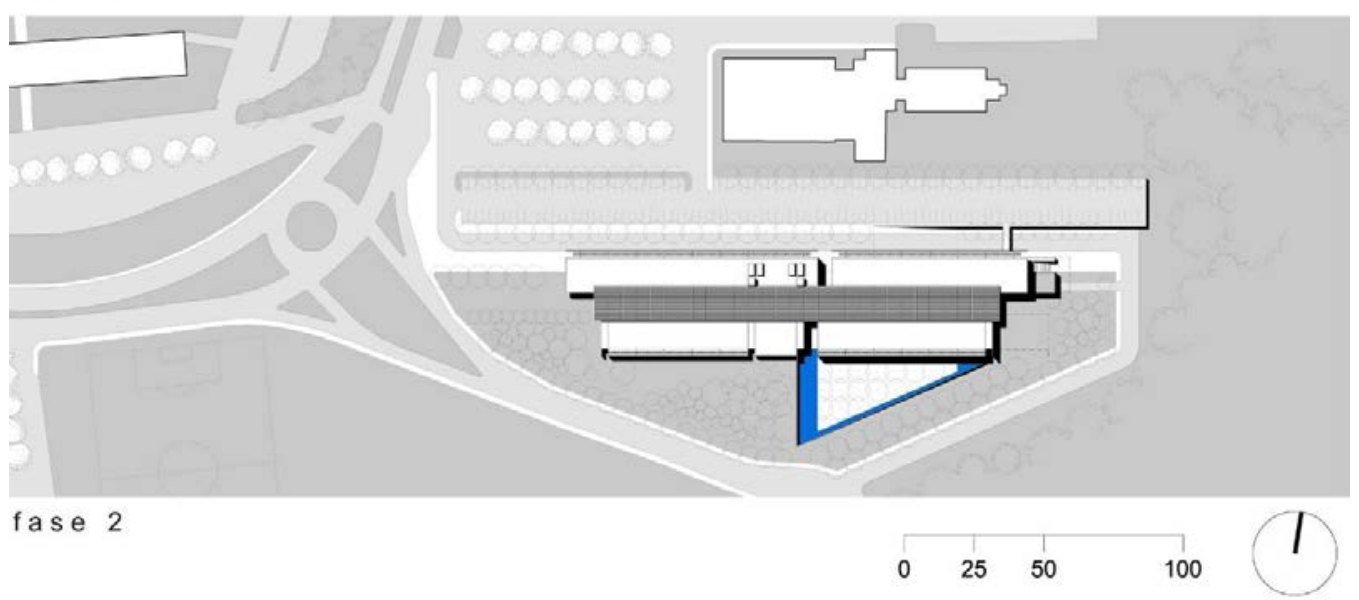

Figura 6 - SAP Labs Brazil, implantação dos blocos do edifício em duas fases, escala 1/3.000

Fonte: imagem gentilmente cedida pela Eduardo de Almeida Arquitetos Associados e Shundi Iwamisu Arquitetos Associados. 
O edifício é composto de dois blocos paralelos, em forma de lâminas alongadas no eixo leste-oeste, com subsolo, térreo, primeiro e segundo pavimentos (Figuras 7 e 9). As fachadas menores dos dois blocos, leste e oeste, são empenas cegas, e as fachadas principais, norte e sul, receberam áreas de vidro de piso a teto, protegidas por dispositivos de sombreamento. Vazios e ambientes entre os blocos também são sombreados (Figura 8).

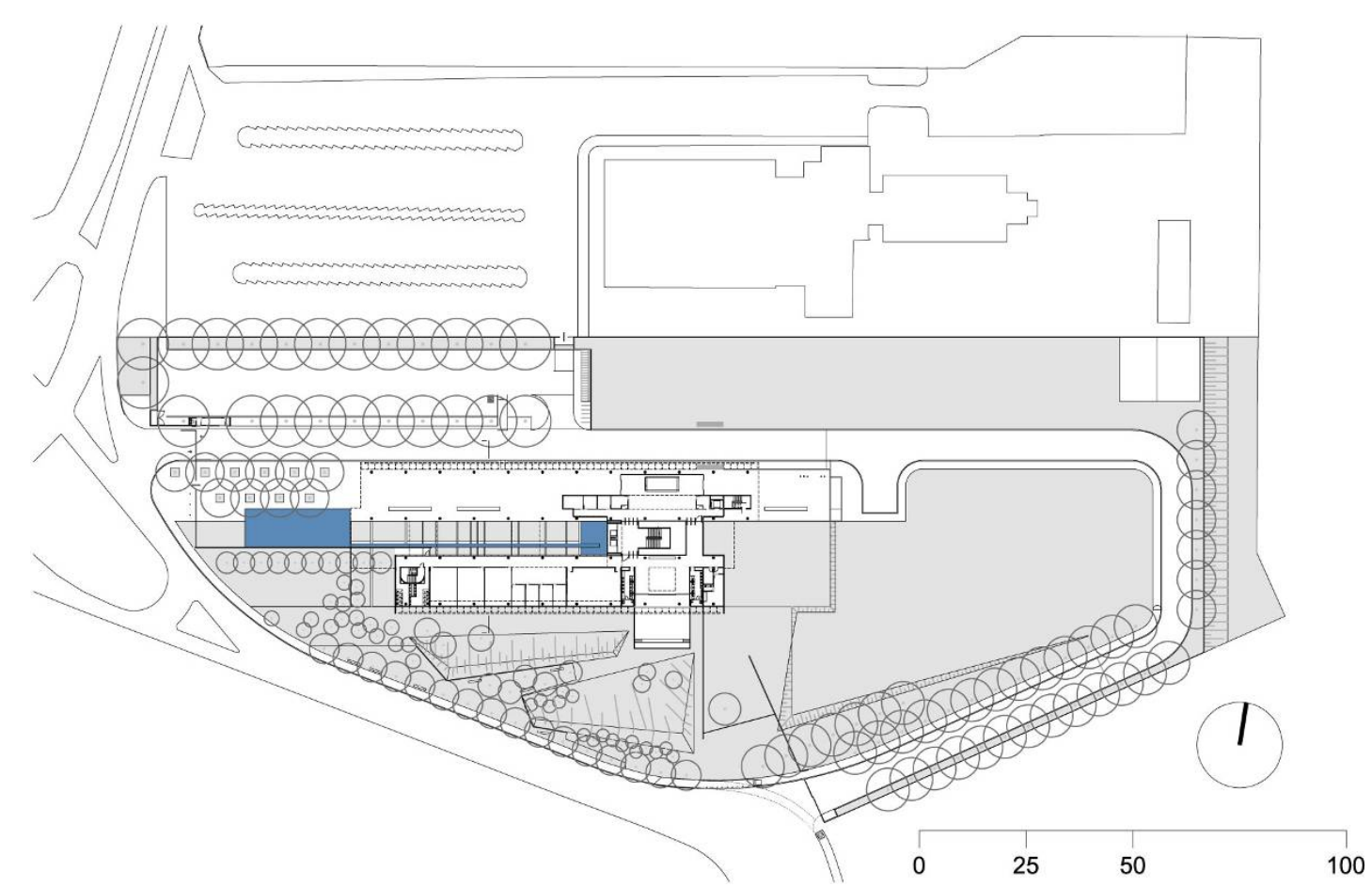

Figura 7 - SAP Labs Brazil, implantação, escala 1/2.000

Fonte: imagem gentilmente cedida pela Eduardo de Almeida Arquitetos Associados e Shundi Iwamisu Arquitetos Associados.

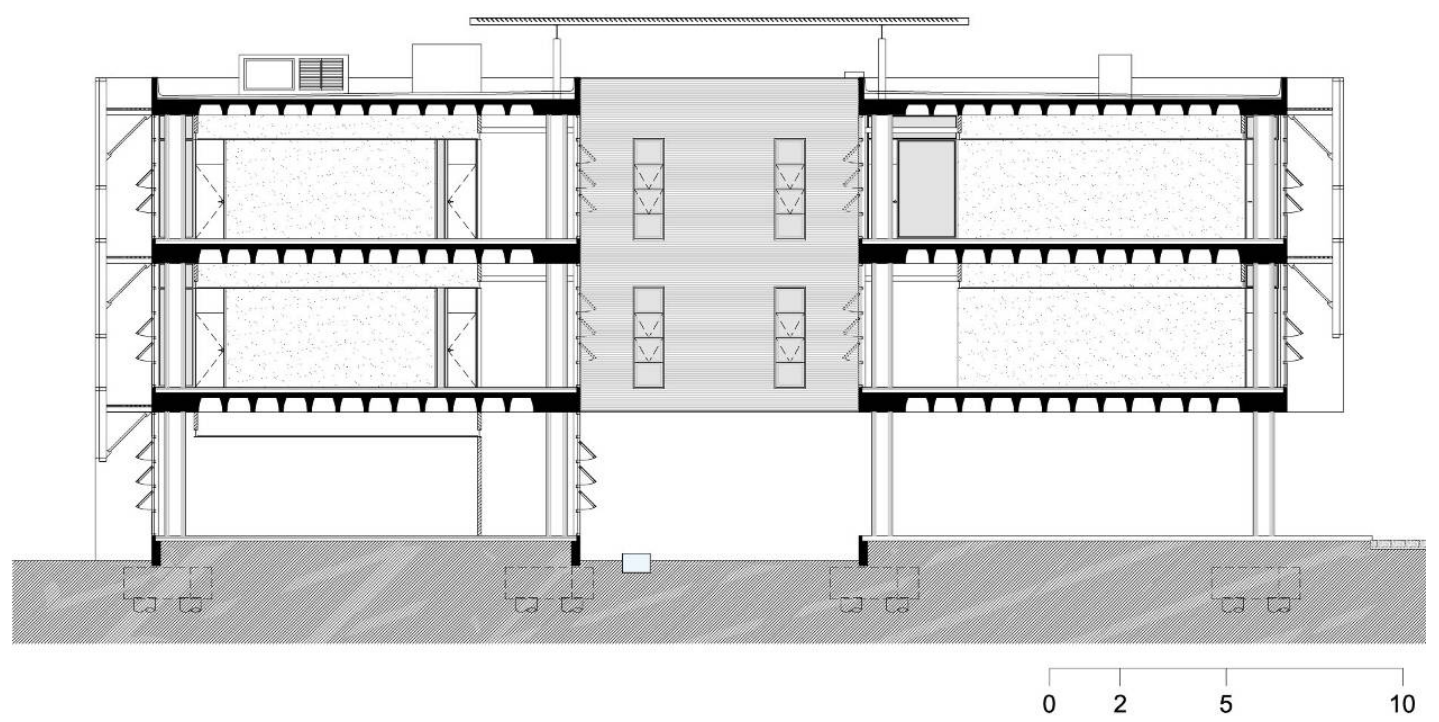

Figura 8 - SAP Labs Brazil, corte transversal, escala 1/250

Fonte: imagem gentilmente cedida pela Eduardo de Almeida Arquitetos Associados e Shundi Iwamisu Arquitetos Associados. 


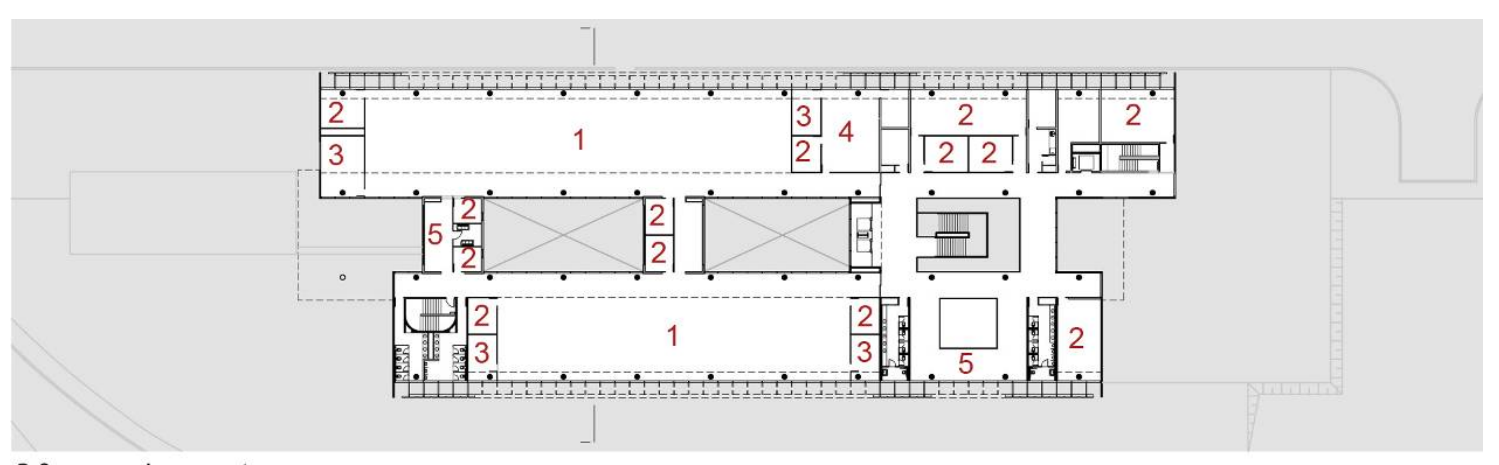

\section{$2^{\circ}$ pavimento}

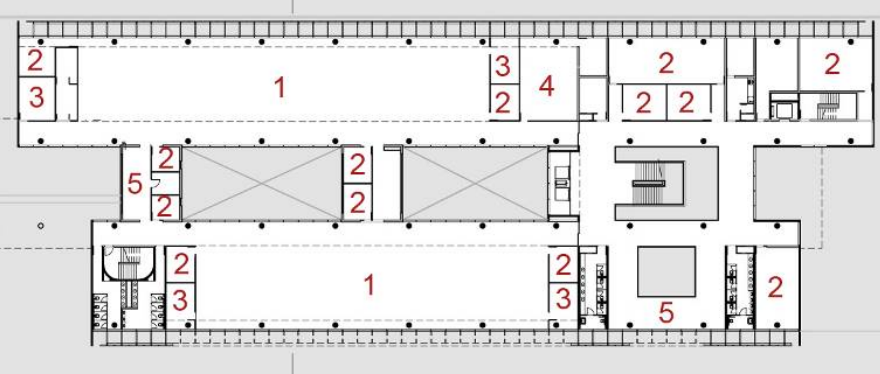

$1^{\circ}$ pavimento

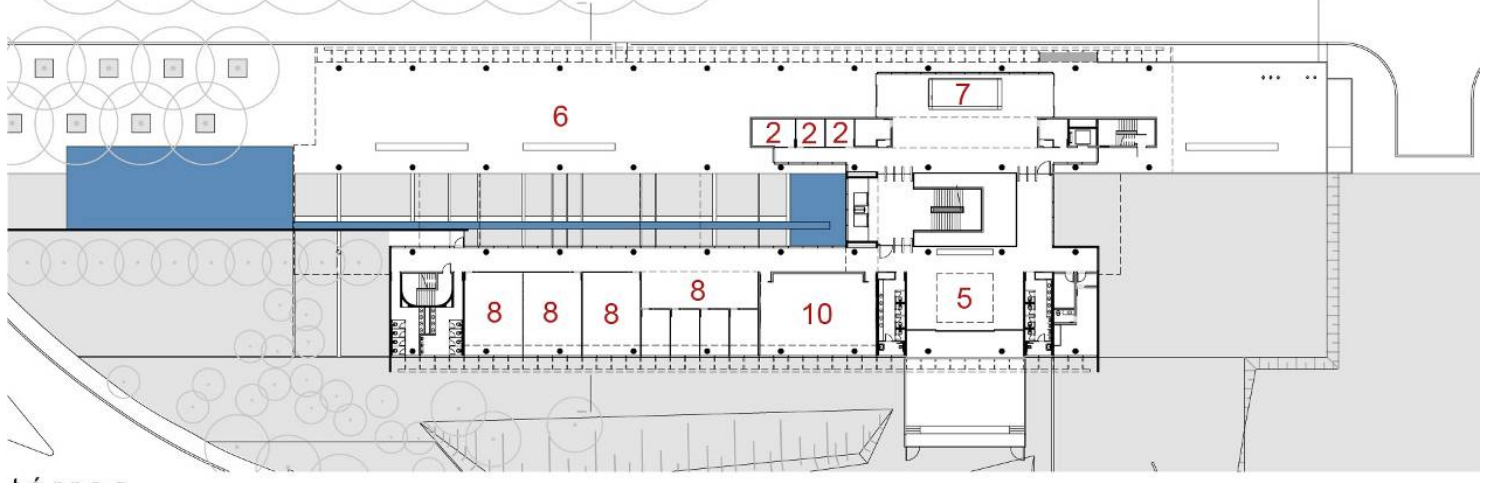

tér reo

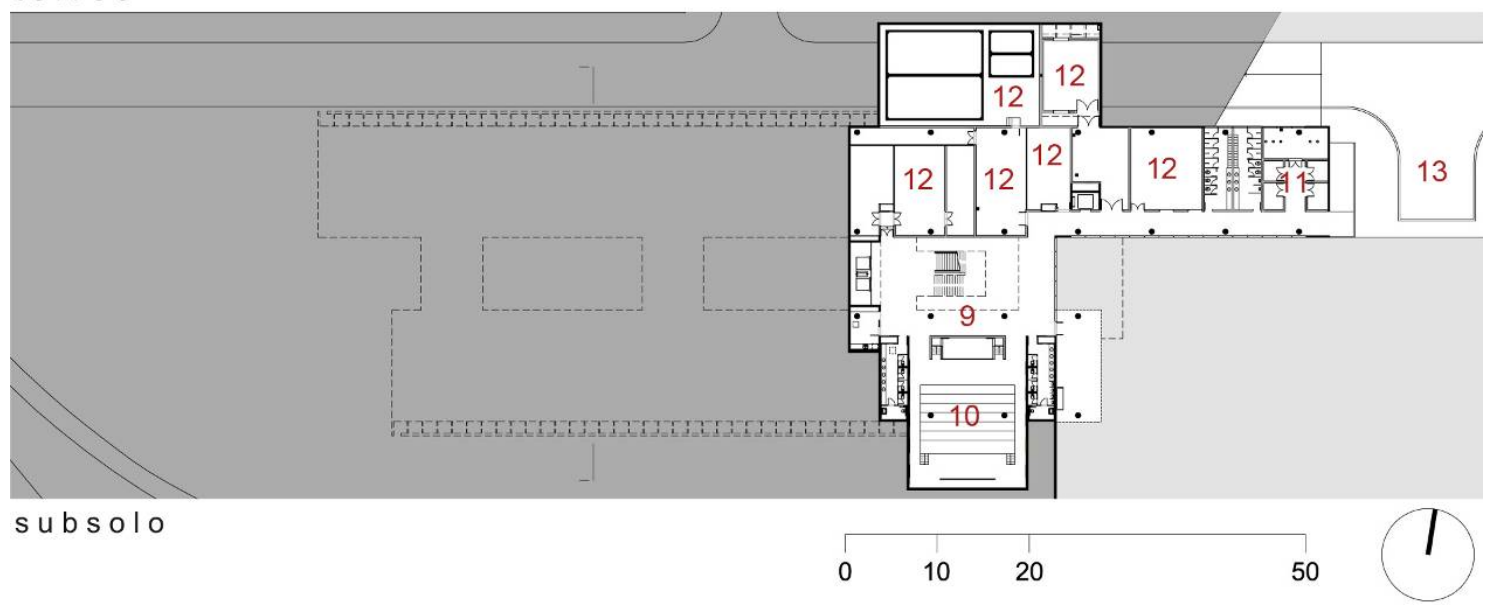

(1) área de trabalho (2) reunião (3) diretoria (4) RH (5) café (6) pilotis (7) recepção (8) treinamento

(9) foyer do auditório (10) auditório (11) segurança (12) área técnica (13) carga/descarga

Figura 9 - SAP Labs Brazil, plantas dos pavimentos, escala 1/1.000

Fonte: imagem gentilmente cedida pela Eduardo de Almeida Arquitetos Associados e Shundi Iwamisu Arquitetos Associados. 


\section{Relato do processo}

O recebimento de carta-convite para o concurso do projeto marcou o início da etapa de Estudo Preliminar (início em março de 2007 e entrega em abril do mesmo ano). O programa de necessidades (design brief), elaborado pelo cliente, foi considerado completo e bem caracterizado pelos arquitetos entrevistados. Quanto aos aspectos de desempenho ambiental, foi explicitado o objetivo de obter nível ouro do sistema de avaliação e certificação LEED ${ }^{\mathrm{TM}}$, nível considerado possível de atingir. Os principais conceitos do projeto foram definidos nessa etapa.

Foram realizadas consultorias com a projetista de estruturas; projetistas de instalações elétricas, hidráulicas e de ar condicionado; projetista de paisagismo; consultor de conforto térmico e acústico; e empresa para consultoria LEED ${ }^{\mathrm{TM}}$. Segundo os arquitetos entrevistados, as consultorias visaram principalmente a uma verificação das soluções adotadas e ao prédimensionamento de elementos do projeto (estrutura, componentes, áreas técnicas, etc.), mas a participação do consultor de conforto e da projetista de estruturas foi mais intensa do que é usual em concorrências na modalidade cartaconvite para o projeto. Com o auxílio do consultor, adotaram-se princípios básicos para volumetria, orientação e envoltória, visando minimizar ganhos térmicos indesejados devido à radiação solar e favorecer a ventilação natural. Para a definição da modulação e do tipo de estrutura, a projetista de estruturas realizou estudos de alternativas com estrutura metálica, concreto pré-moldado e concreto moldado in loco, bem como alternativas com pilares recuados e avançados em relação às fachadas, para avaliar os impactos sobre o dimensionamento. Para o concurso, optou-se pelo sistema metálico, recuando-se os pilares em relação às fachadas.

O projeto conceitual desenvolvido foi vencedor da concorrência, e a contratação do escritório de arquitetura, projetistas e consultores marcou o início da etapa de Anteprojeto (início em setembro e entrega em novembro de 2007). A equipe foi ampliada, incluindo também (além dos que participaram do concurso), projetistas de luminotécnica e de automação e consultores de esquadrias e de impermeabilização. Também foi contratada a construtora, com um pacote fechado para custos e prazos, definido a partir do projeto conceitual. Por intermédio da construtora, também foi contratada uma nova empresa, para consultoria LEED $^{\mathrm{TM}}$.

Logo no início dos trabalhos, decidiu-se substituir o sistema estrutural metálico por estrutura de concreto com fôrma do tipo cubeta $^{4}$ (moldado in loco). Segundo a projetista de estruturas, essa alteração foi a principal dificuldade vivenciada por ela, pois levou à necessidade de alteração da modulação adotada no projeto conceitual e, consequentemente, a um redesenho significativo de todo o projeto. Porém, excetuando-se o novo sistema estrutural e modulação, os principais conceitos foram mantidos (volume, orientação e dispositivos de sombreamento).

Os documentos de construção foram elaborados em duas etapas:

(a) Projeto Básico (início em novembro e entrega em dezembro de 2007); e

(b) Projeto Executivo (entrega em janeiro de 2008, com revisões até junho do mesmo ano).

Em novembro, foi contratada uma nova empresa de consultoria, cujo escopo englobou:

(a) consultoria LEED $^{\mathrm{TM}}$;

(b) controle de qualidade na obra e fiscalização (representando o cliente); e

(c) consultorias para questões técnicas específicas, como solicitação de estudos e simulações de eficiência energética.

Essa contratação visou aumentar a capacidade de controle do cliente, quanto aos vários aspectos do projeto e obra, com ênfase para aqueles relacionados ao processo de certificação LEED ${ }^{\mathrm{TM}}$. A empresa de consultoria LEED ${ }^{\mathrm{TM}}$ contratada através da construtora deixou, então, de participar do processo, ficando a nova empresa de consultoria responsável pelas tarefas relacionadas à certificação.

A partir daí, ocorreu um novo direcionamento do processo em relação aos requisitos de certificação, realizando-se uma verificação mais rigorosa da redução no uso de energia devido aos sistemas previstos no projeto. Para tanto, foi contratada uma empresa para realizar uma série de estudos e simulações de desempenho energético. Estas últimas revelaram que o sistema previsto em VRV com cassetes embutidos no forro não seria suficientemente eficiente para atingir a redução necessária, o que impossibilitaria a obtenção de certificação $\operatorname{LEED}^{\mathrm{TM}}$. Chegou-se a 9\% de redução em relação ao modelo-base de referência, conforme normas ASHRAE/IESNA Standard 90.1 (AMERICAN..., 2004), quando o pré-requisito exige redução de no mínimo 14\%.

Várias simulações pontuais foram feitas para levantar as alternativas de soluções, em diferentes

\footnotetext{
${ }^{4} \mathrm{Na}$ ocasião, a construtora considerou esse sistema o mais
} adequado quanto aos custos e prazos de execução estipulados. 
subsistemas do edifício, por exemplo, tipos de vidro e relação entre áreas opacas e envidraçadas nas fachadas. Mas poucas alterações puderam ser incorporadas na arquitetura, já que o projeto estava demasiado avançado. A solução encontrada foi passar a considerar a ventilação natural, como o modo passivo de um sistema híbrido de condicionamento (ativo e passivo). A adoção de sistema de ar condicionado, com central de água gelada e fan-coils com VAV (Volume de $\mathrm{Ar}$ Variável), resultou em uma redução de $12 \%$ no uso de energia. Considerando-se as épocas do ano em que a ventilação natural é suficiente para garantir o conforto térmico, a redução atingiu pouco mais de $14 \%$, atendendo-se o pré-requisito para certificação.

\section{Resultados alcançados}

Apesar das dificuldades enfrentadas, a meta explicitada no edital de concorrência, de obter certificação nível ouro no sistema $\mathrm{LEED}^{\mathrm{TM}}$, foi alcançada. Essa ferramenta possui uma interface amigável ao usuário, devido a sua estrutura bastante simples, que concede créditos para o atendimento de critérios preestabelecidos. Na versão $2.2^{5}$, há sete pré-requisitos obrigatórios e 69 pontos possíveis ${ }^{6}$ (US GREEN..., 2005). Os prérequisitos e requisitos para obtenção de créditos são distribuídos em seis grupos:

(a) sítios sustentáveis;

(b) uso eficiente de água;

(c) energia e atmosfera; materiais e recursos;

(d) qualidade do ambiente interno; e

(e) inovação e processo de projeto.

Para o SAP Labs Brazil, foram contemplados prérequisitos e requisitos nos seis grupos.

Quanto ao grupo energia e atmosfera, uma redução de pouco mais de $14 \%$ no uso de energia durante a operação, em relação ao modelo-base de referência, garantiu o atendimento ao pré-requisito e aos pontos obrigatórios relacionados. As simulações de desempenho energético revelaram que a volumetria e a orientação norte e sul das fachadas principais foram eficazes para a redução de ganhos de calor indesejados. A configuração

\footnotetext{
${ }^{5}$ A versão piloto $\left(\operatorname{LEED}^{\mathrm{TM}} 1.0\right)$ foi lançada em 1998, a versão LEED $^{\mathrm{TM}}$ V2.1, em 2002, e a versão LEED ${ }^{\mathrm{TM}} \mathrm{V} 2.2$, em 2005 (US GREEN..., 2005). Em abril de 2009, a versão atual LEED ${ }^{\mathrm{TM}} \mathrm{v} 3$ foi lançada (US GREEN..., 2009). Este trabalho descreve a versão 2.2, por ser a versão de registro do estudo de caso 01, e bastante semelhante à versão 2.1, em que o estudo de caso 02 foi registrado.

${ }^{6}$ Dependendo da pontuação atingida, o edifício será certificado em um dos seguintes quatro níveis: Certificado - de 26 a 32 pontos; Prata - de 33 a 38 pontos; Ouro - de 39 a 51 pontos; ou Platina - de 52 a 69 pontos.
}

adotada, com blocos alongados no eixo leste-oeste de $12 \mathrm{~m}$ de largura, também favorece a iluminação natural e a ventilação cruzada. Uma questão controversa, no entanto, é a relação entre áreas opacas e envidraçadas, pois uma área envidraçada menor poderia resultar em menores ganhos de calor. Esse dado foi confirmado nas simulações de desempenho energético realizadas, mas estas ocorreram tarde no processo, quando vários elementos da arquitetura já estavam consolidados, incluindo as esquadrias piso a teto nas áreas de trabalho e circulações. Em contrapartida, a especificação e o detalhamento dos dispositivos de sombreamento e vidros foram cuidadosamente desenvolvidos e verificados ao longo do processo, em colaboração entre equipe de arquitetura, consultores de conforto térmico, consultor de esquadrias e especialista responsável pelas simulações de desempenho energético.

Com base nas simulações, os elementos que mais influenciaram na redução do consumo de energia foram os sistemas de condicionamento e de iluminação artificial. Para o segundo, foram adotadas luminárias e lâmpadas de alta eficiência, incluindo lâmpadas halógenas e LEDs ${ }^{7}$. O sistema é integrado por meio de automação, protocolo DALI $^{8}$, sensores de presença, sensores de luminância e temporizadores.

Para o uso eficiente de água, foram adotados dispositivos economizadores e uma estação de tratamento de esgoto (ETE) de alto desempenho, para tratamento de todo o esgoto do edifício e reúso da água em descargas e irrigação. Quanto às áreas externas, foram especificadas espécies nativas e adaptadas ao bioma local, que demandam quantidades menores de água e menos cuidados com a correção do solo. Pontos do grupo sítios sustentáveis foram obtidos devido à redução do efeito de ilha de calor, com a especificação de pisos externos claros e brita branca sobre as lajes impermeabilizadas das coberturas. A seleção de materiais de menor impacto ambiental seguiu requisitos relacionados aos grupos materiais $e$ recursos e qualidade do ambiente interno. Foram adotados materiais regionais, materiais reciclados e/ou recicláveis, madeira com certificação FSC e materiais com baixo índice de compostos orgânicos voláteis (COVs), como, por exemplo, tintas, resinas e adesivos.

\footnotetext{
${ }^{7}$ Light Emitting Diodes.

${ }^{8}$ Digital Addressable Lighting Interface.
} 


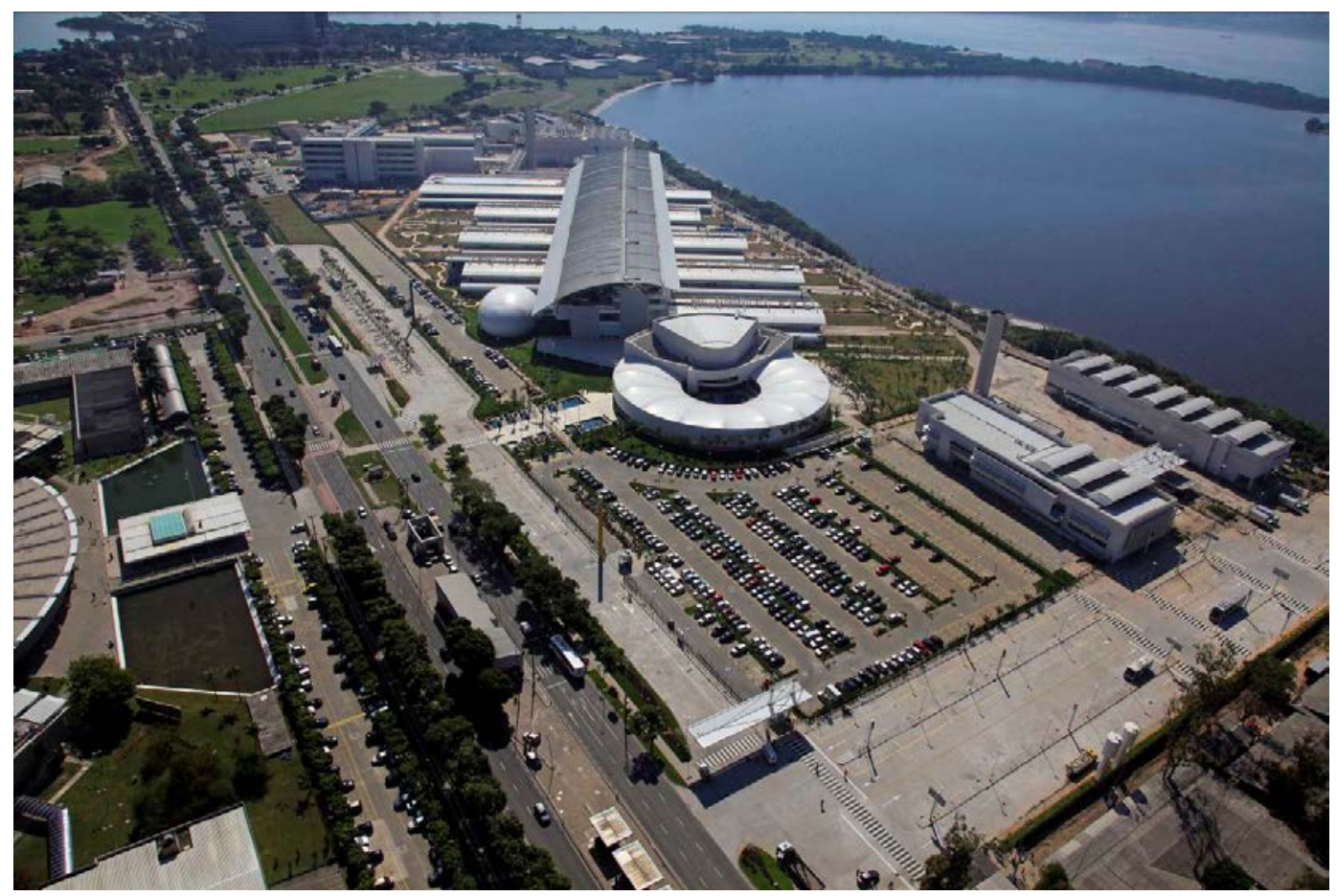

Figura 10 - Ampliação do Cenpes

Fonte: imagens gentilmente cedidas pela Zanettini Arquitetura.

\section{Estudo de caso 2: ampliação do CENPES (CENPES II)}

O segundo estudo de caso é o processo de projeto de um novo complexo de edifícios, para ampliação do Centro de Pesquisas e Desenvolvimento Leopoldo Américo Miguez de Mello (Cenpes), da Petrobras, na Ilha do Fundão, Rio de Janeiro (Figura 10).

O projeto de arquitetura da ampliação foi desenvolvido pela Zanettini Arquitetura S.A., em coautoria com José Wagner Garcia. O projeto foi iniciado em março de 2004, após recebimento de carta-convite para o concurso do projeto. A construção foi iniciada em dezembro de 2005, e uma primeira etapa de implantação foi inaugurada em outubro de 2010. A entrega de uma segunda etapa de implantação está prevista para 2020. A área construída total é de aproximadamente $120.000 \mathrm{~m}^{2}$, em terreno de $183.194,27 \mathrm{~m}^{2}$. O processo de certificação $\mathrm{LEED}^{\mathrm{TM}}$ foi protocolado em 2004, sendo este o primeiro projeto brasileiro registrado no sistema?
Foi definido para o projeto um partido predominantemente horizontal, intercalando espaços internos e espaços de transição (cobertos e abertos), e estabelecendo uma forte integração entre as áreas externas e internas. O complexo de edifícios é estruturado e organizado por um eixo principal norte-sul, que resolve ao mesmo tempo a circulação de pessoas e a distribuição de todas as instalações (Figura 11). Alongado sobre esse eixo, foi definido o Edifício Central (ver corte transversal na Figura 12), sob o qual, no nível térreo, é resolvido o acesso aos blocos de laboratórios, lâminas térreas alongadas em eixos leste-oeste, perpendiculares ao eixo principal (ver corte transversal na Figura 13).

\footnotetext{
${ }^{9}$ Dado coletado em entrevista da pesquisa.
} 


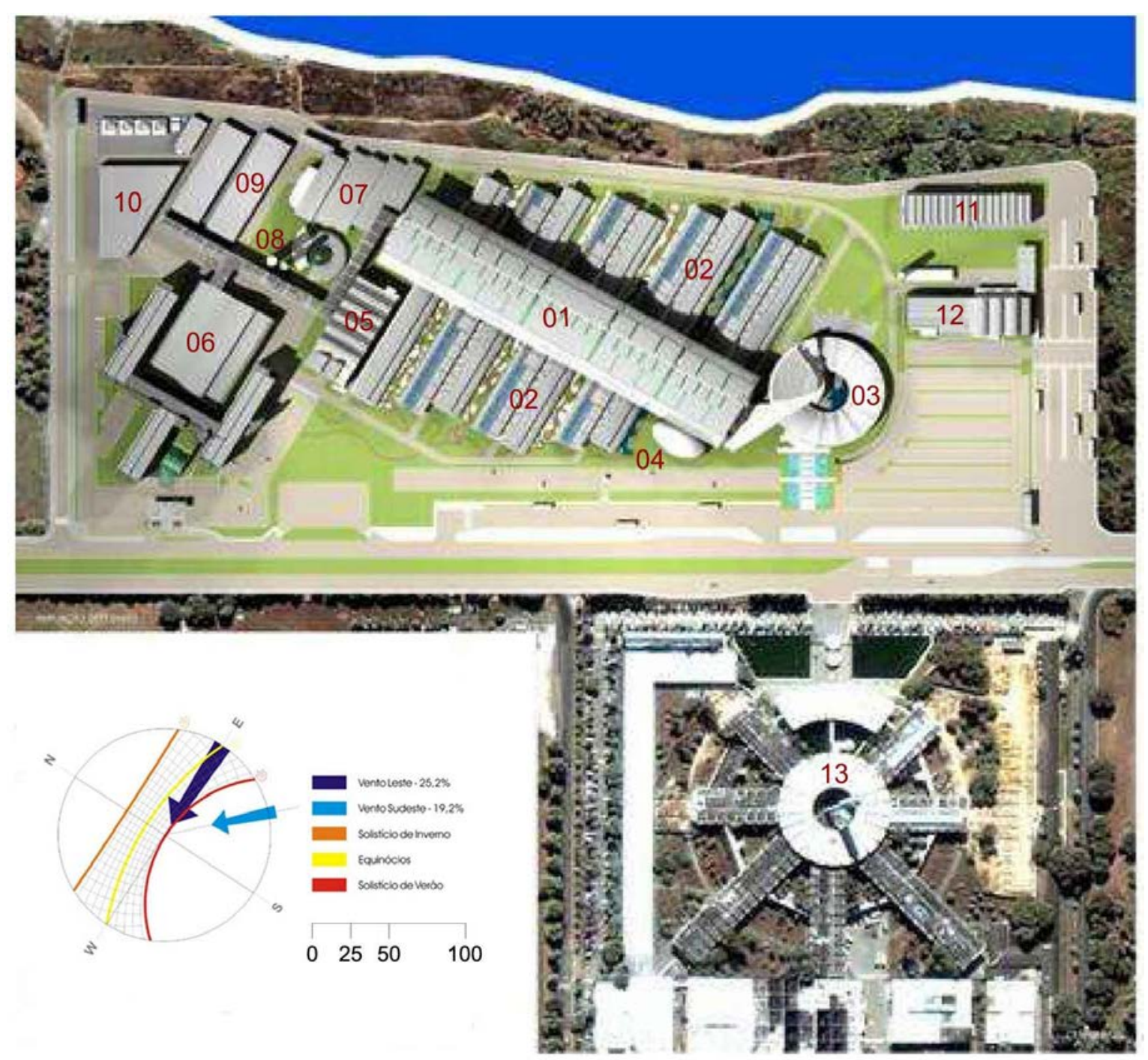

Figura 11 - Ampliação do Cenpes, implantação

Fonte: imagem gentilmente cedidas pela Zanettini Arquitetura.

Nota: implantação - escala 1/ 5000.

Legenda:
(01) Edifício Central;
(02) Laboratórios;
(03) Centro d eConvenções;
(04) CRV;
(05) Planta-Piloto;
(06) CIPD/ RIO;
(07) Restaurante;
(08) Orquidário;
(09) Central de Utilidades;
(10) ETRA;
(11) Empreiterópolis;
(12) Manutenção, oficinas, depósitos; e
(13) CENPES existente. 


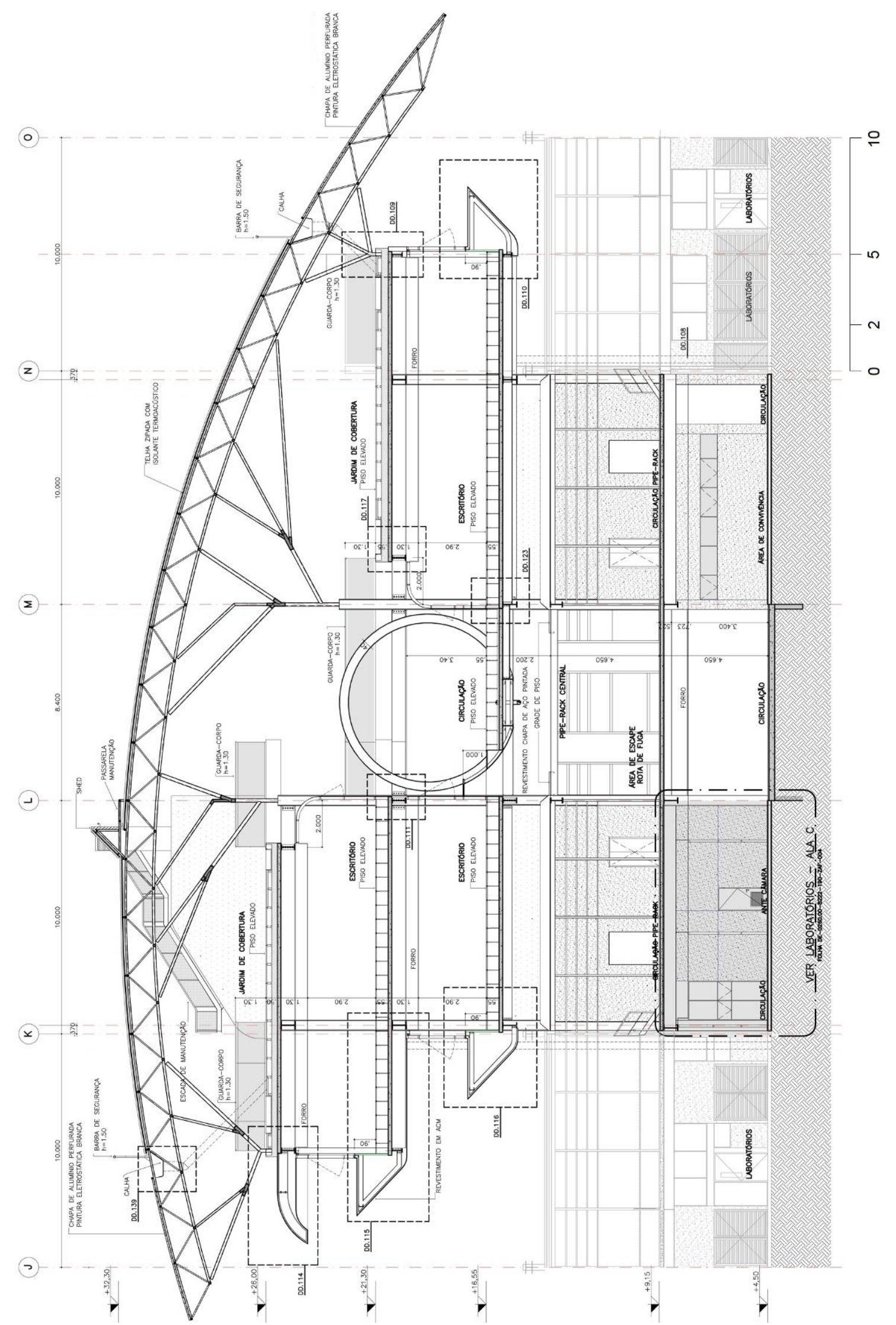

Figura 12 - Ampliação do Cenpes, corte transversal do Edifício Central, escala 1/250

Fonte: imagem gentilmente cedida pela Zanettini Arquitetura. 


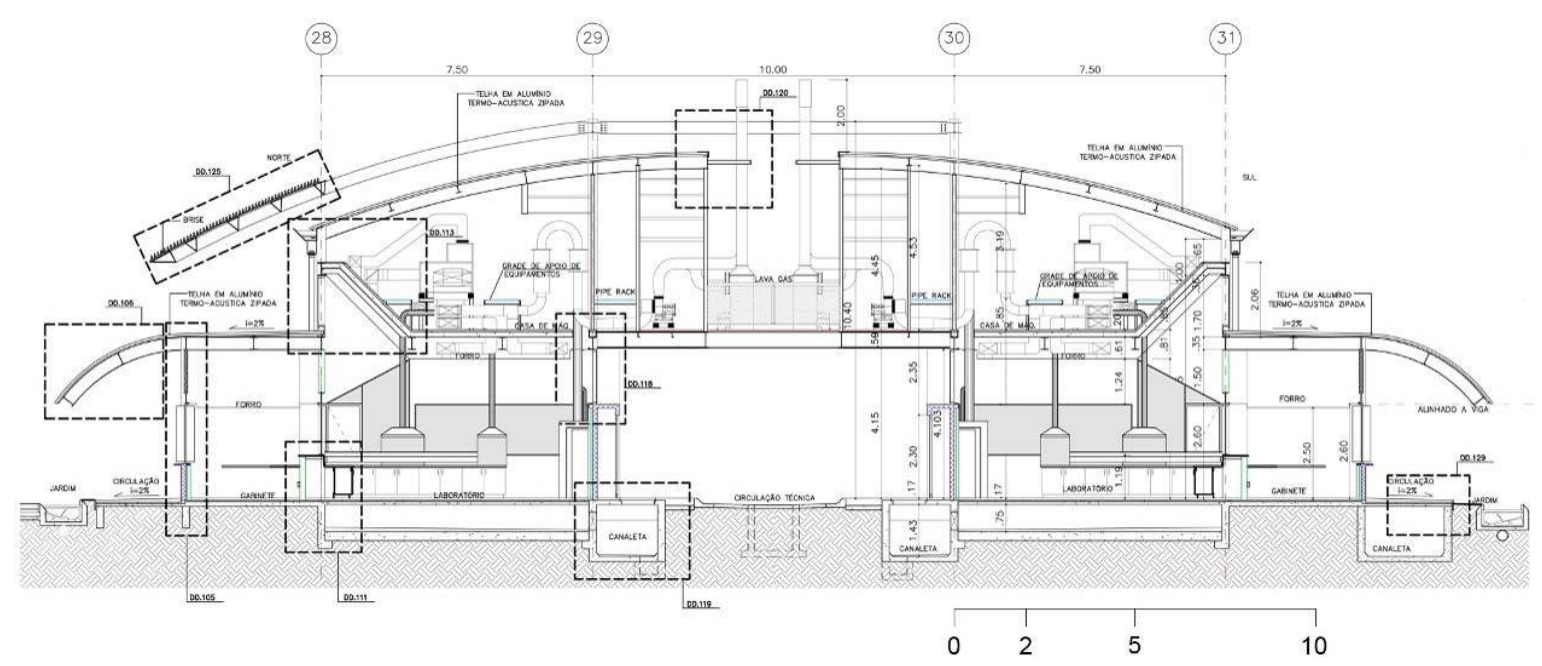

Figura 13 - Ampliação do CENPES, corte transversal de um bloco de laboratório, escala 1/250

Fonte: imagem gentilmente cedidas pela Zanettini Arquitetura.

\section{Relato do processo}

Em etapa anterior ao projeto, foi elaborado, pela Petrobras, o Memorial Descritivo para a contratação e licitação do projeto. Trata-se de um extenso documento, bastante detalhado, que reúne os objetivos do empreendimento, o programa de necessidades, critérios, dados, diretrizes e requisitos de desempenho, bem como procedimentos e normas específicas da empresa, para o desenvolvimento do projeto e produção. Um fato inovador foi a inclusão de critérios para o desempenho ambiental do conjunto de edifícios do complexo. O conceito de ecoeficiência, termo empregado pela Petrobras, presente no edital, incluiu os seguintes tópicos mandatários (GONÇALVES; DUARTE, 2005):

(a) orientação solar adequada;

(b) forma arquitetônica adequada aos condicionantes climáticos locais e padrão de uso para a minimização da carga térmica interna;

(c) materiais construtivos das superfícies opacas e transparentes termicamente eficientes;

(d) superfícies envidraçadas com taxa de WWR (Window Wall Ratio) adequada às condições de conforto térmico e luminoso internos;

(e) proteções solares externas adequadas às fachadas;

(f) ventilação natural, com aproveitamento adequado dos ventos para resfriamento e renovação do ar interno;

(g) aproveitamento da luz natural;

(h) uso da vegetação;

(i) sistemas para uso racional de água e reúso; e (j) materiais de baixo impacto ambiental, dentro do conceito de desenvolvimento sustentável.

Também foram compiladas informações detalhadas do terreno e local, incluindo dados climáticos. Entre os objetivos, foi explicitada a intenção de obter certificação LEED ${ }^{\mathrm{TM}}$.

Com base no memorial, quatro escritórios de arquitetura foram convidados a participar da concorrência para o projeto. Inicialmente, os candidatos foram chamados para participar de um workshop, com uma semana de palestras, sobre os aspectos de ecoeficiência que deveriam ser atendidos ${ }^{10}$. Para tanto, foi formada uma equipe de professores de quatro universidades ${ }^{11}$. Durante a etapa de concurso foi mantido um canal aberto de comunicação com os professores, no qual perguntas dos candidatos eram respondidas e disponibilizadas para todos.

A etapa de Estudo Preliminar (início em março e entrega em maio de 2004) correspondeu à elaboração do projeto conceitual para o concurso. Uma equipe multidisciplinar de projetistas e de consultores foi constituída, logo no início dos trabalhos, incluindo arquitetura; consultoria e pesquisa em ecoeficiência (para avaliação de térmica, iluminação, acústica e eficiência energética); e projetistas de estruturas, instalações elétricas, hidráulicas e ar condicionado. Os principais conceitos do projeto foram definidos nessa etapa.

\footnotetext{
${ }^{10}$ Foram conduzidas palestras sobre os temas de eficiência energética, uso racional e economia de água, seleção de materiais de menor impacto ambiental, redução de desperdícios de materiais, energia solar e certificação LEED ${ }^{\mathrm{TM}}$.

${ }^{11}$ Universidade Federal de Santa Catarina (UFSC), Universidade Estadual de Campinas (Unicamp), Universidade de São Paulo (USP) e Universidade Federal do Rio Grande do Sul (UFRS).
} 
De forma diversa da prática usual em concursos por carta-convite para projetos, o trabalho multidisciplinar foi muito intenso, com várias reuniões de trabalho. A equipe de ecoeficiência, por exemplo, trabalhou muitos dias no escritório de arquitetura. Em um primeiro momento, realizou-se uma apresentação das condicionantes climáticas e ambientais do local, com um diagnóstico e indicação de estratégias principais de soluções, incluindo adoção de blocos alongados, privilegiando orientações norte e sul para as fachadas principais, considerando uma menor incidência de radiação solar; adoção de sombreamento; e ventilação natural, considerando as direções predominantes dos ventos. Em seguida, procurou-se atender às necessidades do projeto, com o suporte de análises e simulações simplificadas. A participação da projetista de estruturas também foi intensa. Uma modulação de 10x10 m foi estabelecida em função da otimização da concentração de cargas e estacas, considerandose as características do solo. Já a participação dos projetistas de instalações foi fundamental para o desenvolvimento do conceito de um piso técnico para pipe racks, atravessando todo o complexo e distribuindo todas as instalações.

Em julho, a equipe de projetistas foi informada de que o projeto foi o vencedor da concorrência. Houve, então, um período de aproximadamente quatro meses de negociação do contrato global, muito complexo, já que o escritório de arquitetura subcontratava todos os demais projetistas e consultores. Nesse período, foi realizada uma revisão do Estudo Preliminar, com a participação de equipe da Petrobras, incorporando-se uma série de alterações, principalmente em relação à implantação dos edifícios, acessos e sistema viário.

Com a assinatura do contrato, iniciou-se a etapa de Projeto Executivo (início em novembro de 2004 e últimas entregas em junho de 2006). Inicialmente, o contrato previu sete meses para essa etapa, que se estenderam para 19 meses aproximadamente. Não houve datas fixas de entregas gerais, pois os desenhos foram sendo cadastrados separadamente, conforme procedimentos do sistema de gestão definido pela Petrobras. Nessa etapa, a equipe foi ampliada, incluindo também (além dos que participaram do concurso) projetistas de automação, luminotécnica e paisagismo; consultores de esquadrias, acústica e impermeabilização; e consultora técnica para implantação de Plano da Qualidade para o projeto. O escritório de arquitetura ficou responsável pela coordenação global de todos os projetos e gestão do processo, até a entrega final do conjunto de documentos para licitação e construção. O cliente, Cenpes, participou intensamente do processo e teve também o apoio de um robusto corpo técnico da Petrobras (prestadores de serviço internos), com arquitetos e engenheiros, englobando várias disciplinas.

Os trabalhos dos projetistas e consultores foram bastante intensos. A equipe de ecoeficiência conduziu avaliações muito detalhadas, com o uso de ferramentas computacionais avançadas de simulação, englobando conforto térmico, iluminação, acústica e eficiência energética (GONÇALVES; DUARTE, 2005). Esses estudos apoiaram o desenvolvimento do projeto, sendo importantes, por exemplo, para orientar o detalhamento dos dispositivos de sombreamento e fornecer parâmetros para a especificação de vidros e materiais das vedações (externas e internas). A equipe de ecoeficiência também foi responsável pela verificação do projeto quanto ao atendimento a requisitos para certificação $\mathrm{LEED}^{\mathrm{TM}}$.

\section{Resultados alcançados}

Durante a coleta de dados, muitos créditos da avaliação com a ferramenta LEED $^{\mathrm{TM}}$ ainda estavam incertos, principalmente por dependerem de extensa documentação proveniente da obra, ainda em andamento. No entanto, independentemente do resultado da avaliação, esta investigação revelou a presença de estratégias agressivas, visando ao desempenho ambiental do complexo.

Quanto ao grupo atmosfera e energia, dados indicando a eficiência energética atingida ainda não estão disponíveis, mas as soluções de projeto adotadas foram embasadas em critérios corretos e detalhadamente verificadas, com ferramentas de simulação. A orientação, com fachadas principais leste-oeste, adotada para o Edifício Central, apesar de menos favorável, justifica-se por outros critérios, incluindo a vista para a baía e a possibilidade de privilegiar a orientação dos laboratórios, dispostos em eixos perpendiculares ao eixo principal norte-sul. A conceituação e o detalhamento da envoltória e dispositivos de sombreamento levaram em consideração a geometria da insolação, minimizando-se a penetração de radiação solar direta nos ambientes e otimizando-se a iluminação natural.

Também foi fundamental a adoção de sistemas ativos de alto desempenho, com destaque para a iluminação artificial, com luminárias eficientes integradas à disponibilidade de luz natural, e sistema de ar condicionado, com central de água gelada e distribuição em dutos com VAV. Um exemplo significativo de integração entre os subsistemas do edifício foi a adoção de insuflamento do ar condicionado pelo piso no 
Edifício Central, viabilizada pelas seguintes características do projeto:

(a) pé-direito mais alto;

(b) geometria alongada da edificação;

(c) eficiência do sistema de iluminação artificial; e

(d) especificação adequada dos vidros, isolamentos, coberturas verdes e elementos de sombreamento.

Esses elementos permitiram menores dimensões do sistema de ar condicionado, incluindo dutos menores, passíveis de ser locados dentro do piso elevado. Para tanto, foi fundamental a colaboração entre arquitetura, equipe de ecoeficiência, projetista de ar condicionado, projetista de luminotécnica e consultor de esquadrias.

Em relação ao grupo uso eficiente de água, foram previstos uma estação de tratamento e reúso de água (Etra), para tratamento de todo o esgoto gerado e reúso da água nas torres de resfriamento do sistema de ar condicionado; captação e armazenagem da água da chuva, para uso na irrigação dos jardins e bacias; e dispositivos economizadores. Quanto ao grupo materiais $e$ recursos, a obtenção de créditos, não disponíveis na ocasião, dependia de documentação proveniente da obra que comprovasse, por exemplo, o uso de madeira certificada, de materiais com conteúdo reciclado e materiais de origem, processamento e produção regional.

\section{Análise dos dados}

\section{Posicionamento em relação à referência teórica}

As Figuras 14 e 15 ilustram o posicionamento dos estudos de caso em relação à referência teórica. Para cada etapa dos processos, os ícones em preto representam os elementos metodológicos presentes, enquanto os ícones em cinza representam os ausentes. Também foi indicada a participação dos agentes em cada etapa.

Nos dois processos de projeto não ocorreram compromissos preestabelecidos de implementação de PPIs. Apesar disso, uma presença parcial dos elementos metodológicos que os caracterizam foi constatada em ambos os casos, incluindo a incorporação de requisitos de desempenho ambiental nos editais dos concursos, com a adoção de sistemas de avaliação e certificação ambiental; maior interação entre as disciplinas de projeto e consultoria, a partir das etapas de Estudo Preliminar; uso de ferramentas computacionais de simulação; e uma intensa participação e motivação dos clientes. Estes tiveram influência significativa sobre os resultados positivos alcançados.

Foram constatadas, porém, em ambos os processos, três diferenças importantes em relação à referência teórica de PPI. A primeira está relacionada ao modelo de contratação dos projetos por meio de concurso fechado, que restringe substancialmente os meios disponíveis nas duas etapas iniciais do processo. As Figuras 14 e 15 revelam que, nos dois casos, na etapa de Levantamento e Programa de Necessidades, quando são definidos os objetivos e metas, apenas o cliente participa, enquanto na etapa de Estudo Preliminar, que corresponde à preparação do material para o concurso, o cliente não pode participar do desenvolvimento e das decisões do projeto. Prazos também são sempre demasiado curtos, impossibilitando, por exemplo, simulações de desempenho energético de diferentes alternativas de soluções. Uma maior presença dos elementos metodológicos ocorreu apenas após as contratações dos projetos, a partir da etapa de Anteprojeto, para o SAP Labs Brazil (Figura 14), e da etapa de Projeto Executivo, para a Ampliação do Cenpes (Figura 15).

A segunda diferença é que, apesar da presença de requisitos de desempenho ambiental claros nos dois processos, não houve discussão e definição consensual de metas específicas e mensuráveis, já que as metas existentes foram definidas apenas pelos clientes.

Finalmente, a terceira é que, em ambos os processos, a tarefa de integrar os subsistemas coube principalmente à equipe de arquitetura, também responsável pela coordenação, quando no PPI as interações ocorrem também transversalmente entre as várias disciplinas, realizando-se reuniões multidisciplinares com a equipe completa, não só gerenciais e de compatibilização, mas também de conceituação e desenvolvimento das soluções e sistemas. 


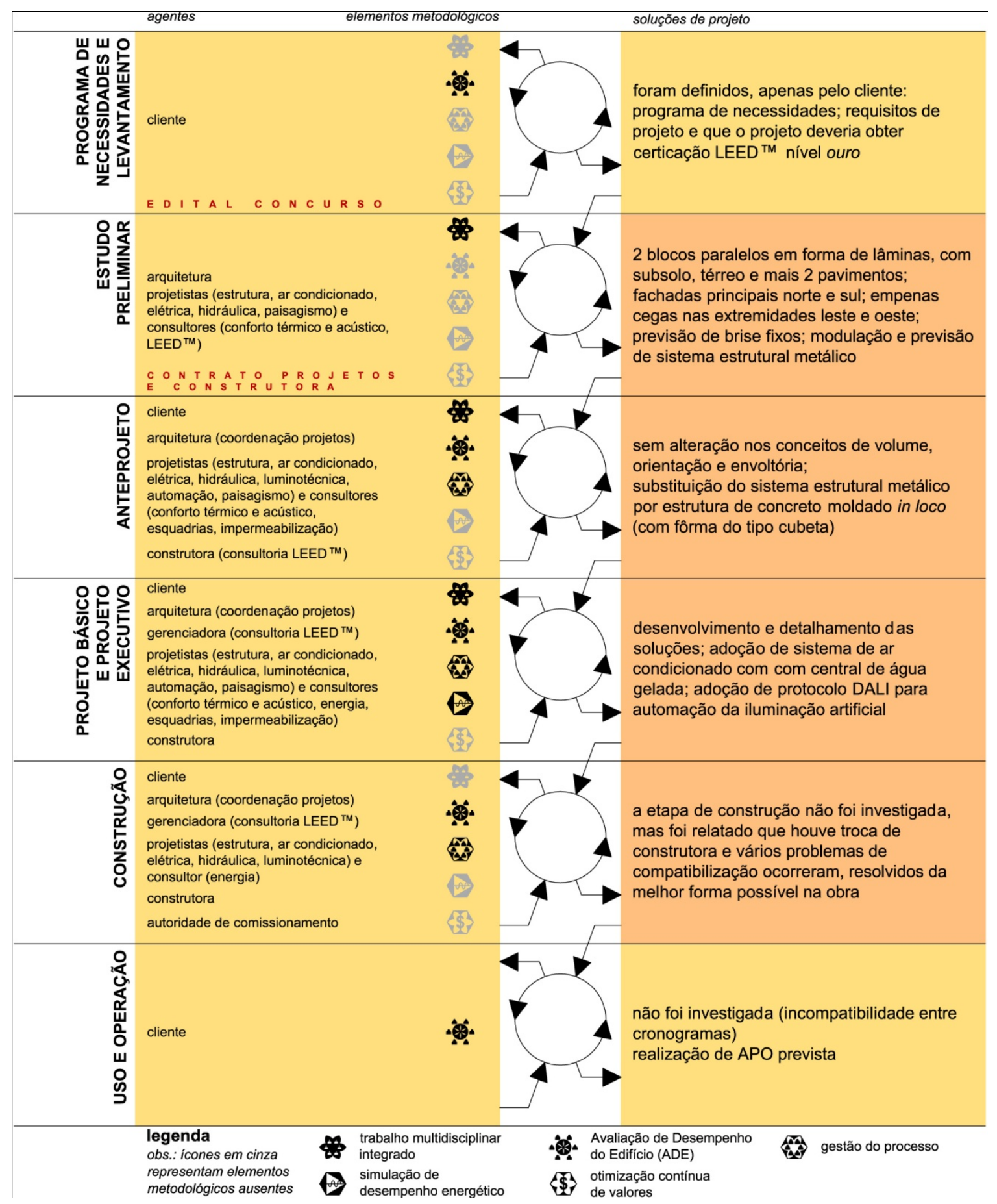

Figura 14 - Posicionamento do processo de projeto do SAP Labs Brazil em relação à referência teórica de PPI

Fonte: baseada em Figueiredo (2009, p. 164). 


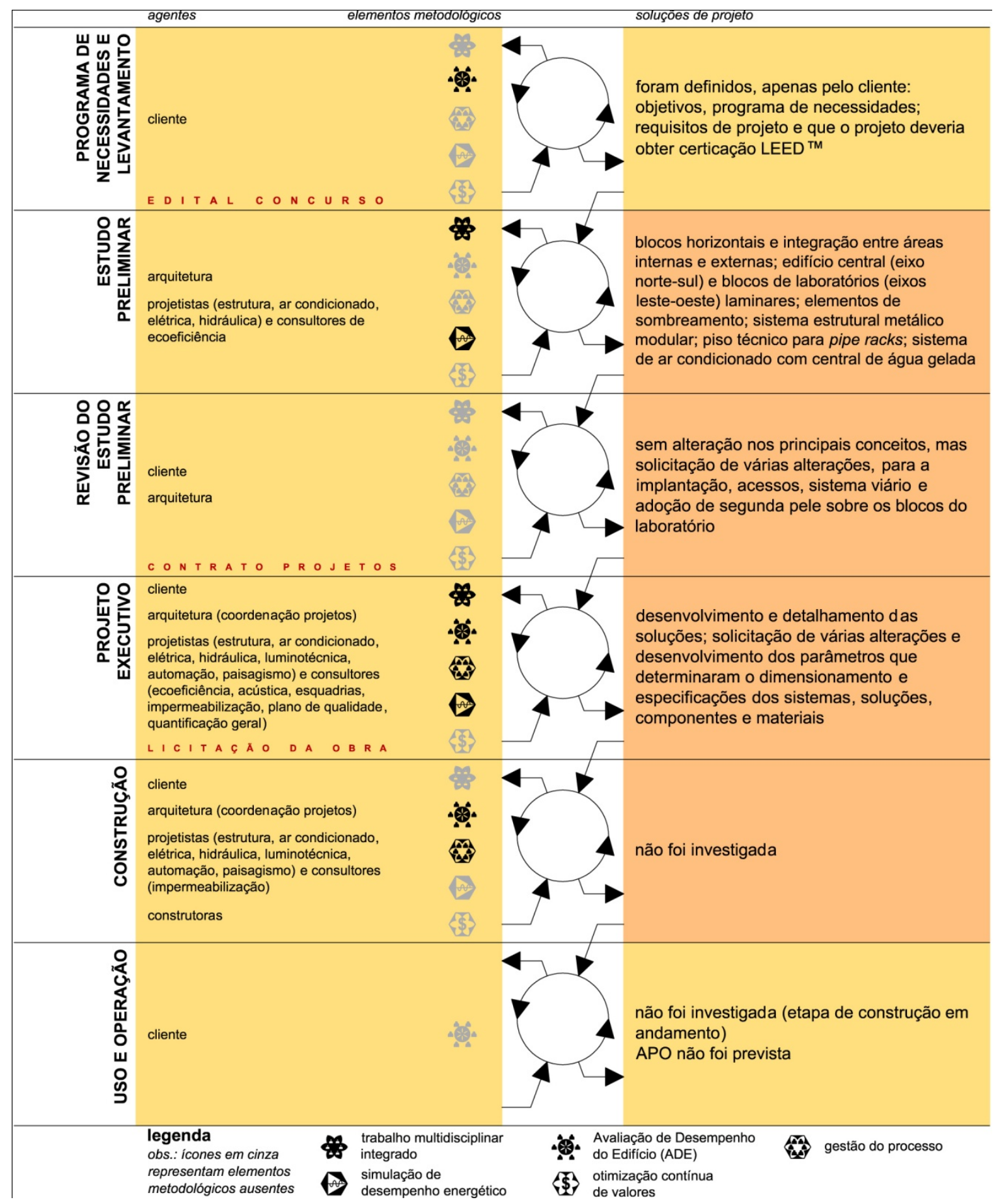

Figura 15 - Posicionamento do processo de projeto da Ampliação do Cenpes em relação à referência teórica de PPI

Fonte: baseada em Figueiredo (2009, p. 174).

\section{Lições aprendidas}

As lições aprendidas, sistematizadas a partir dos pontos positivos e das dificuldades dos estudos de caso, são resumidas a seguir.

\section{Interação entre as disciplinas desde o início do processo}

A inclusão de projetistas e consultores e uma maior interação entre as disciplinas que o usual, a partir da etapa de concurso, tiveram impactos bastante positivos nos dois casos, possibilitando que a conceituação das principais características 
dos projetos levasse em conta princípios básicos para o conforto ambiental e eficiência energética. Por exemplo, volumetrias alongadas em eixos leste-oeste foram privilegiadas, configurando fachadas principais norte e sul e plantas estreitas, minimizando ganhos térmicos indesejados e favorecendo a iluminação e ventilação naturais. Também foi importante, em ambos os casos, uma intensa participação do cliente nos processos, com grande envolvimento e motivação. Uma integração maior poderia ser alcançada, ainda, com a realização de reuniões multidisciplinares, com a equipe completa, para compartilhamento de informações e desenvolvimento conjunto das soluções.

\section{Estabelecimento de metas de desempenho ambiental e uso de sistemas de avaliação e certificação ambiental}

A presença desses elementos e a elaboração de programas de necessidades bastante completos foram pontos de grande importância. No entanto, para a incorporação de metas mais agressivas, é fundamental que seja realizada uma discussão e definição consensual das metas de desempenho, além de uma tradução dos requisitos e princípios em critérios, unidades de medida e bases de referência, que não ocorreram em nenhum dos casos. Sistemas de avaliação e certificação ambiental podem auxiliar essas tarefas, pois fornecem parâmetros para a definição de metas claras e mensuráveis, mas, para tanto, é necessário que todos compreendam muito bem as características e os requisitos do sistema e participem intensamente das tarefas relacionadas, desde o início.

\section{Modelos de contratação para os projetos e obra}

Em ambos os casos, a contratação dos projetos por meio de concurso fechado restringiu substancialmente os meios disponíveis nas duas etapas iniciais. No caso da Ampliação do Cenpes, a contratação da obra por meio de licitação também impossibilitou a presença de representantes da etapa de construção nas etapas de projeto, o que posteriormente levou a problemas de integração entre essas etapas. Esses fatos indicam a necessidade de seleção de modelos de contratação para os projetos e obra, de forma a garantir que todos os agentes participem, ou ao menos sejam representados, desde o início e ao longo de todas as etapas, incluindo cliente, projetistas, consultores e construtora.

\section{Sistemas de gestão}

A adoção de procedimentos de sistemas de gestão da qualidade foi um ponto positivo nos dois estudos de caso. No entanto, para o caso da Ampliação do Cenpes, foram constatadas dificuldades relacionadas à passagem direta da etapa do concurso para o Projeto Executivo, no qual as entregas de projetos eram cadastradas separadamente. Foi relatado que retrabalhos significativos decorreram disso. Inadequações dos cronogramas também foram constatadas em ambos os estudos de caso. Essas dificuldades evidenciam a importância de definirem-se de forma adequada as etapas e os marcos de passagem, bem como os escopos, honorários, cronograma de atividades e prazos. A discussão e a definição consensual desses elementos podem ser um recurso eficaz nesse sentido.

\section{Uso de ferramentas de simulação de desempenho energético}

A presença deste elemento foi muito importante em ambos os casos. Na Ampliação do Cenpes, simulações detalhadas puderam embasar o desenvolvimento de várias soluções do projeto, durante a etapa de Projeto Executivo. Esses estudos e os ajustes deles derivados teriam sido inviáveis sem o uso de ferramentas computacionais avançadas de simulação. No entanto, na etapa de concurso da Ampliação do Cenpes foram realizadas apenas simulações simplificadas, devido à restrição de tempo para a entrega do material. Para o caso do SAP Labs Brazil, as simulações foram realizadas apenas a partir da etapa de Projeto Básico, visando principalmente a uma verificação quanto ao atendimento do pré-requisito para certificação. Como nas etapas iniciais as oportunidades de alterações são muito maiores, o uso dessas ferramentas para a análise de alternativas é fundamental.

\section{Aprendizado}

Nos dois casos este foi um dos principais pontos positivos relatados pelos entrevistados, não só para consolidação de novas práticas, por parte dos agentes envolvidos, mas também para a produção e o registro das informações que sirvam de referência para outros projetos e equipes.

\section{Conclusões}

Uma contribuição importante desta pesquisa dá-se devido à atenção dedicada aos processos de projeto dos empreendimentos investigados, apresentandose relatos dos eventos mais significativos, e não apenas a descrição dos resultados finais. 
Conclusões a partir de análises comparativas entre dois processos, com características e contextos diversos, devem ser formuladas com precaução, verificando-se cuidadosamente a pertinência dos argumentos. Entretanto, as duas investigações revelaram características comuns aos dois processos, incluindo pontos positivos e dificuldades, o que reforça a validade das lições aprendidas e discutidas como referência para futuros projetos.

Nos dois estudos de caso, constatou-se a presença parcial dos elementos metodológicos que caracterizam PPIs. Os elementos presentes foram essenciais para o alcance das metas definidas, mas os resultados positivos demandaram esforço e tempo muito superiores aos previamente estimados. As lições aprendidas sugerem que grande parte das dificuldades observadas poderia ser evitada, ou ao menos minimizada, pela incorporação dos elementos ausentes. A implementação completa do PPI leva a uma maior eficiência do processo, o que torna possível o alcance de metas mais agressivas de desempenho ambiental.

\section{Referências}

7 GROUP; REED, B. G. The Integrative Design Guide to Green Building: redefining the practice of sustainability: redefining the practice of sustainability. New Jersey: John Wiley \& Sons, 2009.

AMERICAN INSTITUTE OF ARCHITECTS. Integrated Project Delivery: a guide. Version 1. [S.l.]: AIA National; AIA California Council, 2007.

AMERICAN SOCIETY OF HEATING, REFRIGERATING AND AIRCONDITIONINGENGINEERS.

ANSI/ASHRAE/IESNA Standard 90.1: energy standard for buildingsexcept low-rise residential. Atlanta, 2004.

BUSBY; PERKINS + WILL; STANTEC CONSULTING. Roadmap For the Integrated Design Process. Vancouver: BC Green Building Roundtable, 2007.

FABRICIO, M. M. Projeto Simultâneo na Construção de Edifícios. São Paulo, 2002. Tese (Doutorado em Engenharia) - Escola Politécnica, Universidade de São Paulo, São Paulo, 2002.
FIGUEIREDO, F. G. Processo de Projeto Integrado para Melhoria do Desempenho Ambiental de Edificações: dois estudos de caso. Campinas, 2009. Dissertação (Mestrado) Faculdade de Engenharia Civil, Universidade Estadual de Campinas, Campinas, 2009.

FIGUEIREDO, F.; SILVA, V. G. Processo de Projeto Integrado: recomendações para empreendimentos com metas rigorosas de desempenho ambiental. Revista PARC: Pesquisa em Arquitetura e Construção, Campinas, v. 1, n. 5, nov. 2010.

GONÇALVES, J. C. S.; DUARTE, D. H. S. CENPES II: o novo centro de pesquisas da Petrobras, no Rio de Janeiro: uma atitude ambiental inovadora na arquitetura brasileira. In: ENCONTRO NACIONAL SOBRE CONFORTO DO AMBIENTE CONSTRUÍDO, 8.; ENCONTRO LATINO-AMERICANO SOBRE CONFORTO DO AMBIENTE CONSTRUÍDO, 4., Maceió, AL, 2005. Anais... Maceió, AL: 2005. p. 828-837.

INTERNATIONAL ENERGY AGENCY. Integrated Design Process: a guideline for sustainable solar-optimised building design. Berlim: IEA, 2003.

KIBERT, C. Sustainable Construction: green building design and delivery. Hoboken: John Wiley \& Sons, 2005.

MALIN, N. Integrated Design. Environmental Building News, v. 13, n. 11, nov. 2004.

MELHADO, S. B. Qualidade do Projeto na Construção de Edifícios: aplicação ao caso das empresas de incorporação e construção. São Paulo, 1994. Tese (Doutorado em Engenharia) - Escola Politécnica, Universidade de São Paulo, São Paulo, 1994.

MELHADO, S. B. Gestão, Cooperação e Integração Para Um Novo Modelo Voltado à Qualidade do Processo de Projeto na Construção de Edifícios. São Paulo, 2001. Tese (Livre-Docência) - Escola Politécnica, Universidade de São Paulo, São Paulo, 2001.

PREISER, W. F. E.; VISCHER, J. C. (Eds.). Assessing Building Performance. Oxford: Butterworth; Heinemann, 2005.

ROMANO, F. V. Modelo de Referência Para o Gerenciamento do Processo de Projeto Integrado de Edificações. Florianópolis, 2003. Tese (Doutorado - Programa de Pós-Graduação em Engenharia de Produção) - Universidade Federal de Santa Catarina, Florianópolis, 2003. 
TORCELLINI, P. et al. Evaluation of LowEnergy Design and Energy Performance of the Zion National Park Visitor Center. Golden: National Renewable Energy Laboratory, 2005.

TORCELLINI, P. et al. Lessons Learned From Case Studies of Six High-Performance Buildings. Golden: National Renewable Energy Laboratory, 2006.

US GREEN BUILDING COUNCIL. LEED ${ }^{\circledR}$ for New Construction \& Major Renovation.

Version 2.2. 2005. (For Public Use and Display).

US GREEN BUILDING COUNCIL. New

Construction: reference guide. Leadership in

Energy and Environmental Design. Version 2.2.

Third Edition, 2007.
US GREEN BUILDING COUNCIL. LEED 2009

For new Construction and Major Renovations. Leadership in Energy and Environmental Design. 2009. (For Public Use and Display).

YIN, R. K. Estudo de Caso: planejamento e métodos. Tradução de Daniel Grassi. 3. ed. Porto Alegre: Bookman, 2005.

\section{Agradecimentos}

Os autores agradecem à Capes, pela bolsa concedida, à SAP Labs Brazil e Petrobras, pelas autorizações para o uso de imagens e informações dos estudos de caso; a Eduardo de Almeida Arquitetos Associados, Shundi Iwamisu Arquitetos Associados e Zanettini Arquitetura, pelas imagens gentilmente cedidas; e aos avaliadores anônimos, por suas contribuições no refinamento deste trabalho.

Revista Ambiente Construído

Associação Nacional de Tecnologia do Ambiente Construído

Av. Osvaldo Aranha, 99 - 3o andar, Centro

Porto Alegre - RS - Brasil

CEP $90035-190$

Telefone: +55 (51) 3308-4084

Fax: +55 (51) 3308-4054

www. seer. ufrgs. br/ ambienteconstruido

E-mail: ambienteconstruido@ufrgs.br 